\title{
DESPUÉS DEL 'FINAL' DE LAS VILLAE ENTRE EL MIÑO Y EL DUERO (sS. VII-X): Comunidades 'fructuosianas', hábitat rupestre y 'aldeas'
}

\author{
Jorge LÓPEZ QUIROGA
}

Universidad Autónoma de Madrid

1. 1. Un punto de partida indispensable: el poblamiento rural tardo-antiguo entre el Miño y el Duero (siglos V-VII d. C.) ${ }^{1}$ :

El estudio del poblamiento rural durante la Antigüedad tardía entre el Miño y el Duero (Figura 1), debe atender al análisis de dos parámetros que evolucionan sincrónicamente: por una parte, la dinámica interna de los patrones de asentamiento romanos (localizada fundamental, pero no exclusivamente, en las uillae, uici y castella); por otra, la acción de los cambios y las transformaciones aculturizadoras que sobre la evolución del poblamiento introducirá el proceso de cristianización rural entre el siglo $\mathrm{V}$ y principios del VIII

\footnotetext{
${ }^{1}$ Trabajo realizado en el marco del Programa Ramón y Cajal financiado por el Ministerio de Educación y Ciencia con fondos FEDER. El mismo se ha efectuado también dentro del proyecto Estudio analítico de los asentamientos rurales en 'Hispania' (siglos IV-VII d. C.): una propuesta de trabajo interdisciplinar, financiado por la Universidad Autónoma de Madrid y del que es investigador principal Jorge López Quiroga.; así como de la Acción Integrada hispano-italiana Tras el 'final' de las 'villae' en el noreste de la Península Ibérica y en el norte de Italia a partir del análisis micro-regional (siglos VII-XI), entre las Universidades Autónoma de Madrid y Ca'Foscari de Venecia, financiado por el Ministerio de Educación y Ciencia.
}

(PERGOLA, 1999). Ello no quiere decir, naturalmente, que presentemos una imagen demasiado estática en lo que a evolución del poblamiento y ocupación del espacio se refiere. Al contrario, durante ese período de casi cinco siglos (entre el s. III d. C. y la primera mitad del VII d. C.), la propia evolución intrínseca del poblamiento romano (tanto de los asentamientos en llanura tipo uici, uillae o similares, como de los de altura tipo castra o castella) dará lugar a una serie de transformaciones, no tanto en lo que respecta a los patrones de asentamiento, que siguen ajustándose al binomio altura/llanura, sino en la morfología y configuración interna de los mismos.

El desarrollo tardío, en comparación con otras áreas de la Península y de fuera de ella (VALENTI, 2003; FRANCOVICH-HODGES, 2004; HAMEROW, 2004), del sistema de uillae que tendría lugar de forma generalizada a partir de siglo III d. C. (TRANOY, 1981), ha debido contribuir probablemente a que dichos asentamientos se encuentren plenamente activos, e incluso muchos de ellos en franca expansión, a principios del siglo $\mathrm{V} \mathrm{d}$. C. (RIPOLL-ARCE, 2000; LÓPEZ QUIROGARODRÍGUEZ MARTÍN, 2000-2001; CHAVARRÍA, 
2004; LÓPEZ QUIROGA, 2006). A pesar de la carencia, tantas veces señalada, de informaciones cuantitativamente importantes, es posible afirmar, desde el punto de vista cualitativo, que la red de uillae entre el Miño y el Duero no desapareció a principios del siglo $\mathrm{V}$ d. C. Indudablemente, los progresos en el conocimiento de la cronología de las producciones cerámicas tardo-antiguas y su cada vez más frecuente aparición en los asentamientos urbanos y rurales del noroeste peninsular, han supuesto un verdadero tournant en la investigación sobre este período, aunque el registro estratigráfico que documente los niveles tardo-antiguos sigue planteando todavía enormes problemas (FERNÁNDEZ OCHOA- MORILLO CERDÁNLÓPEZ QUIROGA, 2005). No obstante, podemos afirmar que el mundo rural tardo-antiguo (entre principios del siglo V y el VIII d. C.) entre los ríos Miño y Duero se caracterizaría por:

I. La continuidad ocupacional de una gran parte de los asentamientos romanos de llanura tipo uillae o similares (al igual que los uici o fora) "bajoimperiales", que estarían "activos" entre los siglos III-VI y hasta un momento indeterminado del VII d. C. Por lo tanto, la dispersión característica del hábitat rural romano se mantendría. No existe, entre el Miño y el Duero, ningún asentamiento de este tipo excavado en su totalidad. Ello nos priva, sin duda, de una visión más precisa de esa aparente continuidad ocupacional que observamos en el espacio de algunas uillae con materiales que permitirían enmarcar las estructuras exhumadas en un arco cronológico que sobrepasa el siglo V d. C., sin que podamos conocer con exactitud el momento final de su ocupación a falta de un registro arqueológico fiable. Para el conjunto del territorio entre el Miño y el Duero, hemos contabilizado unos 40 lugares (Figura 2) ${ }^{2}$, en

${ }^{2}$ Esa cifra no pretende reflejar el número de todas las uillae existentes entre Miño y Duero. Tan sólo representa las que hemos recogido hasta el año 2000. Como ya hemos dicho, una profundización de los trabajos de prospección arqueológica dispararía de inmediato las cifras obtenidas, ofreciendo una densidad de uillae mucho mayor de la que cabría suponer en razón de la condición "periférica" que ha caracterizado a amplias áreas del noroeste peninsular. Por ejemplo, sólo para el alto valle del Támega (limitándonos a la parte actualmente española del mismo) y el alto Limia es posible hablar, con los datos de que disponemos actualmente, fruto de trabajos de prospección en ese territorio, de más de medio centenar de asentamientos de llanura asimilables a establecimientos rurales tipo uillae. Y se trata, naturalmente, de una cifra aproximada, pero que por si sola supera la que ofrecemos para todo el conjunto del territorio entre Miño y Duero. los que sería posible asegurar la presencia de un asentamiento rural de llanura tipo uillae ${ }^{3}$ puesto que, o bien se han logrado descubrir estructuras, o bien los elementos que aparecen en superficie denotan una entidad lo suficientemente importante (columnas, capiteles, estucos, mosaicos o fragmentos de ellos, etc.) como para ser identificadas como tales. La distribución de ese casi medio centenar de uillae dejaría traslucir con claridad la estructuración y vertebración del territorio a partir de tres ejes fundamentales (Figura 2): por una parte, los núcleos o aglomeraciones principales y secundarias (las ciuitates, los uici y los fora, pero también las mansiones viarias), destacando entre ellos las áreas en torno a Braga (en el curso medio del Câvado), Tongobriga (entre el Sousa y el Támega), Chaves (en el Alto Támega), Panonias (entre las estribaciones orientales de la Serra do Marão y la Serra de Vilarinho), al Forum Gigurrorum (en torno al tramo medio del Sil) y Aquis Querquennis (en el curso medio del Limia) (Fig. 4); por otra, los ejes de comunicaciones terrestres (la red viaria principal y secundaria) y los principales cursos fluviales (el Miño, el Limia, el Câvado, el Támega y, en menor medida, el Tua y el Sabor); finalmente, las áreas mineras (especialmente Três Minas y en torno a los tramos finales del Tua y del Sabor).

Ahora bien, otra cuestión bien diferente, y para nosotros crucial, es la de intentar determinar cuántos de esos asentamientos rurales identificados (con muchas salvedades por nuestra parte) como uillae han permanecido más allá del siglo $\mathrm{V}$ d. C. Nuestra impresión, aunque mejor deberíamos decir nuestra intuición, es que una gran parte de las mismas continuaría en actividad durante todo el siglo $\mathrm{V}$ y VI d. C. y hasta un momento difícil de calibrar con precisión, en torno al VII d. C.

Esta "impresión" se fundamentaría, no obstante, en una serie de casos bien conocidos que mostrarían elementos inequívocos de su mantenimiento funcional $\mathrm{u}$ ocupacional como tales durante ese período: en Forte de Lobelhe (Vila Nova de Cerveira, Fig. 8); San Martín de Dumio (Braga); Martím

\footnotetext{
${ }^{3}$ Vamos a adoptar esa denominación, aunque la misma, como es sabido, no se corresponda con una acepción única para dicho término $\mathrm{y}$, por lo tanto, cubra realidades diversas. En efecto, tanto por su tamaño como por su función o morfología el término villa cubre realidades diversas, aunque siempre hace referencia, en general, a lo que serían "asentamientos rurales de llanura" (RODÍGUEZ COLMENERO, 1977, GORGES, ALARCÂO, PÉREZ LOSADA, MARTINS, BAYARD-COLLET, LENZ, FRIENDSHI- TAYLOR, SMITH, CARANDINI, QUILICI- QUILICI GIGLI).
} 
(Barcelos); Aguas Santas (Santa Eulália de Rio Covo, Barcelos); Meinedo (Lousada); Perrelos (Vila Nova de Famalicâo, Figura 5): Santa María de Vilar (Vila do Conde); Santa Marta (Lucenza, Cualedro); Ouvigo (Blancos) (Fig. 9); Muradella (Mourazos, Verín); Parada de Outeiro (Vilar de Santos); São Caetano (Chaves); Vilarinho das Paranheiras (Chaves); "A Cortinela" (Xinzo de Limia); Santa María de Eja (Penafiel); y Vila Marín (Vila Real). En estos asentamientos rurales tipo uillae la ocupación (con todas las salvedades y precauciones que este tipo de hallazgos requieren dada su problemática contextualización estratigráfica) que se observaría sería posible detectarla por la presencia de cerámica tardía de importación, especialmente en la proximidad de la costa y de los cursos fluviales navegables, o de imitación de aquéllas (más frecuente en las áreas del interior, algo alejadas de los circuitos comerciales). Además de estos asentamientos de llanura tipo uillae, tenemos las aglomeraciones secundarias tipo uici o fora y en ellos constatamos también la continuidad de ocupación más allá de principios del siglo V d. C.: en Aquis Querquennis (Portoquintela, Bande, Fig. 4), en Occulis Calidarum (Caldas de Vizela, Guimarães), Alvarelhos (Trofa, Figura 3), en el Forum Limicorum (Xinzo de Limia) y en el Forum Gigurrorum (A Pobra de Valdeorras, El Barco, Ourense) (PÉREZ LOSADA).

Las uillae, por lo tanto, no desaparecerían todavía totalmente en el s. V d. C., al contrario, su ocupación se mantendría durante ese siglo y prácticamente todo el VI d. C., no pudiendo calificarse ésta de residual (BROGIOLO).

El patrón de asentamiento en la llanura (constituido, además de por las uillae, por los uici y los fora) continuaría su evolución interna y desarrollo iniciados en el siglo III d. C. ${ }^{4}$ II.

${ }^{4}$ Como es evidente, existen diferencias cronológicas en el desarrollo de las villae a lo largo de las diferentes provincias del Imperio. En el caso del noroeste peninsular su desarrollo tardío (especialmente a partir del s. III d. C.) quizás haya permitido un mayor vigencia de este tipo de asentamiento respecto a otras áreas. En efecto, en Italia la ocupación estable tipo villa se verifica desde principios del s. I d. C., consolidándose definitivamente en tiempos de Augusto, observándose una crisis que conllevaría un estancamiento de este tipo de asentamientos en el tránsito del s. II al III d. C., y que se acentuaría en el siglo siguiente, lo que conduciría a su vez a la "desaparición" de las villae en el curso del s. VI d. C. En el caso de la Galia (particularmente en el Norte) y Germania, el desarrollo y consolidación definitiva de las villae tendría lugar algo más tarde que en Italia, en época flavia (hacia mediados del s. I d. C. (LENZ).
El castro (Fig. 6 y 7) se mantendría como patrón de asentamiento en altura (independientemente de si poseen la categoría de castella) (GARCÍA MORENO, 1998) entre principios del siglo V y principios del VIII d. C. Aunque, como es lógico suponer, esta ocupación no se mantendría de forma ininterrumpida sino con ritmos e intensidades distintas en el tiempo y en el espacio. En todo el territorio entre el Miño y el Duero el castro está de manera más o menos uniforme omnipresente no solamente como un "elemento residual del paisaje" sino como una unidad fundamental del poblamiento durante toda la Antigüedad Tardía. Sin negar la evidencia que supone la introducción del sistema de uillae y su papel morfogenético en lo que a ocupación y organización del territorio se refiere, la mítica imagen de una "masiva bajada de la población de los castros a la llanura", como consecuencia de la conquista romana, está destinada a mantenerse más como un topos literario que como un dato que refleje una realidad histórica, por otra parte mucho más compleja.

La idea de una prolongada permanencia ocupacional del castro no es, evidentemente, una "novedad" en el ámbito de la investigación sobre este período en el noroeste peninsular, pero se hace necesario dar un paso más respecto a la obviedad que supone la vitalidad ocupacional del castro durante todo el período tardo-antiguo (GARCÍA MORENO, 1998). En este sentido, debemos intentar diferenciar tipos y momentos de ocupación (STEUER, 1990; HOEPER, 1998; HOEPER-STEUER, 1999) entre aquellos castros que, con una morfología y funcionalidad todavía mal conocidas y definidas, presentan una ocupación entre los siglos V y VIII d. C.

a) Tenemos, en primer lugar, una serie de castros que, aparentemente ${ }^{5}$, presentarían una continuidad de ocupación en las primeras decenas del siglo V d. C. y otros que serían reocupados en esos momentos, tras períodos más o menos prolongados de abandono

\footnotetext{
5 Ya que, evidentemente, no han sido excavados en su totalidad. Estos castros serían: Saceda (Lucenza, Cualedro), Novás (Xinzo de Limia), Sacoias (Baçal, Bragança), Guifões (San Martín de Guifões, Matosinhos), Santomé (Ourense), São Brás (Frazão, Paços de Ferreira), Monte Mozinho (Penafiel), Fontes (Santa Marta de Penaguião, Vila Real), Castelo (Villamartín de Valdeorras), Curralha (Chaves), Falperra (Braga), Eiros (Aboim das Chozas, Arcos de Valdevez), Monte do Castro en Gomdomar (Porto), Monte de Sto. Ovidio (Santa Marina de Arcozelo, Ponte de Lima), São Fins de Ferreira (Paços de Ferreira), "Alto da Fonte do Milho" en Canelas de Douro (Pesso da Régua, Vila Real), y Lanhoso (Póvoa de Lanhoso, Braga).
} 
(Fig. 7). La repartición espacial de estos castros, a pesar de su distribución más o menos uniforme por todo el territorio, permite observar cómo la parte costera del Entre Douro- e-Minho es la que muestra una mayor concentración de asentamientos de este tipo con ocupación en la primera mitad del siglo V. d. C., coincidiendo además con un área donde encontramos una obviamente aleatoria concentración de hallazgos de TSCD, que llegaría a través del Duero hasta Penaguião (castro de Fontes) y tesorillos monetarios con piezas de Arcadio y Honorio (395408 d. C.). Ello vendría a coincidir con el área que constituye la base política y territorial del reino suevo. ¿Puede ello haber influido de algún modo sobre el poblamiento y la ordenación del territorio en este momento? Disponemos de muy pocos y fragmentarios elementos para poder dar una respuesta satisfactoria a esta cuestión ${ }^{6}$. No obstante, a título de hipótesis y en función de la tipología de los hallazgos y de su ubicación espacial, podemos apuntar lo siguiente:

- parecería confirmarse la imagen hidaciana de una "agrupación" de la población local galaico-romana sobre asentamientos de altura tipo castro, denominados por este autor como castra y castella tutiora.

- la relativa "concentración" de castra y castella con este tipo de ocupación o reocupación en el área costera del conventus bracarensis nos mostraría dos aspectos de un mismo fenómeno, que constituye el mantenimiento del castro como unidad de poblamiento:

* por una parte, los tesorillos con monedas de Arcadio y Honorio, nos indicarían que existe una ocupación o reocupación de castros en reacción a la llegada e instalación de los "Suevos" en el 411 y que aquélla es especialmente significativa en torno a Braga y Oporto: es decir, la capital políticoadministrativa de la Gallaecia meridional y núcleo portuario importante y estratégico en la desembocadura del Duero. Ambos lugares, por lo tanto, poseen una importancia geopolítica evidente y constituyen objetivos importantes para quien desee controlar este territorio. La elección de Braga como primera capital del reino suevo y posteriormente de Oporto (el castrum novum), no dejan lugar a dudas en este sentido.

* por otra parte, los hallazgos de fragmentos de

6 Y cono es lógico el hallazgo de cerámicas descontextualizadas en un castro, desconociendo o no existiendo un registro estratigráfico que lo contextualize, no constituye un indicio claro de reocupación o de continuidad de ocupación.
TSCD muestran una ocupación o reocupación de castros con un arco cronológico para este tipo de material que se sitúa entre la segunda mitad del s. IV y la primera mitad del s. V d. C. (HAYES, 1972 y 1980), concentrada en el área costera al Sur del Cavado, en torno a Oporto y al tramo final del Duero. Es decir, en un ámbito espacial ligado a una fuerte actividad comercial de importación durante toda la Tardo-Antigüedad, que no se interrumpe ni se contrae, todo lo contrario, con la llegada e instalación de los "Suevos". Por ello, es factible suponer que existen también razones de tipo económico para la ocupación o reocupación de antiguos castros, puesto que estos contribuirían a asegurar y sobre todo a proteger la intensa actividad comercial y los circuitos que la sustentan, que se detecta en el conjunto del noroeste peninsular durante este período.

-en consecuencia, y sin negar que la llegada e instalación de poblaciones foráneas hacia el $411 \mathrm{~d}$. C. (como los Suevos) haya influido notablemente en el fenómeno de ocupación y reocupación de antiguos asentamientos de altura fortificados tipo castro, resulta también evidente la existencia de una dinámica evolutiva interna al poblamiento rural tardo-romano, que no es ajena a dicho proceso y que, con independencia de factores externos, continuaría su desarrollo durante las primeras décadas del $\mathrm{s}$. $\mathrm{V} \mathrm{d}$. C.

b) A continuación, y en segundo lugar, habría una serie de $\operatorname{castros}^{7}$ que, independientemente de su ocupación o reocupación a principios del siglo $\mathrm{V}$ d. C., se mantendrían activos, no sabemos si permanente $\mathrm{o}$ estacionalmente, durante algunos momentos de los siglos VI y VII d. C. Estos asentamientos fortificados de altura muestran una distribución espacial en relación con el trazado de la red viaria (sobre todo la que atraviesa de norte al sur el territorio entre el Miño y el Duero por el interior, a través de Chaves, y por el área costera _via per loca maritima_, a través de Braga, además de la via nova

${ }^{7}$ Curralha (Chaves), Esturãos (Chaves), Falperra (Braga), Panonias (Vila Real), Portucalem castrum novum (actual Oporto, en la margen derecha del Duero), São Caetano (Chaves), castellum Berese, Cendufe (Arcos de Valdez, Viana do Castelo), Castro Cabanca (Castrelo do Val), Sabroso (Longos, Guimarães), São Torcuato (Guimarães), Pombar (San Esteban de Ribas del Sil, Nogueira de Ramuín), y Fontes (Santa Marta de Penaguião, Vila Real). Sobre el castro de Curralha y su problemática interpretación véase ahora: $\mathrm{R}$. TEIXEIRA, De Aquae Flaviae a Chaves. Povoamento e organização do território entre a Antiguidade e a Idade Media (Dissertação de Mestrado, Faculdade de Letras da Universidade do Porto), Oporto, 1996, p. 77-78 y $167-168$. 
que comunicaba Braga con Astorga) y en los bordes de los grandes sistemas montañosos (Serra do Laboreiro, Serra do Gerês, Serra do Marâo, Serra do Larouco y la parte montañosa oriental de la actual provincia de Ourene), lo que podría indicarnos que algunos de estos castra y/o castella estarían realizando alguna función de tipo militar como puestos de control o vigilancia desde época sueva y, sobre todo, durante la visigoda. Mientras que otros castros, en los que observamos la presencia de vestigios o edificios de tipo cultual en relación con el proceso de cristianización, podrían constituirse como núcleos jerarquizadores desde el punto de vista territorial a nivel de la administración eclesiástica, en correspondencia con las informaciones contenidas en las actas conciliares desde comienzos del s. V. d. C. ${ }^{8}$ y del propio Parroquial Suevo para la segunda mitad del VI d. C.51. Si, en el primer caso, el origen de esa ocupación o reocupación de antiguos castros puede obedecer a razones geopolíticas, en el segundo, estas serían de tipo religioso en relación con el proceso de cristianización rural que actuará sobre la jerarquización de la red de poblamiento preexistente y en la que los castra y/o castella ocuparían, como hemos señalado, un escalón intermedio en la ordenación del territorio entre las civitates, los uici y las uillae (REVUELTA CARBAJO).

c) Por último, y en tercer lugar, otro conjunto de castros $^{9}$ que, también con independencia de que exista o haya existido en ellos una ocupación anterior, se reocuparían aparentemente desde

${ }^{8}$ Concretamente al referirse a los lugares que pueden constituir el asiento de una iglesia fuera del ámbito estrictamente urbano. Ello aparece reflejado en el canon 5 del I Concilio de Toledo (397-400): "uel in loco quo est ecclesia aut castelli aut uiucus au uillae", J. VIVES, Concilios visigóticos e hispano-romanos..., op.cit.

${ }^{9}$ En los que hallamos conjuntos de pequeños cementerios excavados en la roca (Fig. 12): castro de San Salvador dos Penedos (Allariz), "Alto do Louredo" (Louredo, Amarante), Santa Marina (Casanova, Armeses, Maside), Donões (Vila Real), Monterrei, "As Chás" (Oimbra), "Coto d'Astrés" (Vilar, Ourense), Sanfins (Sanfins de Ferreira, Paços de Ferreira), Venade (Ferreira, Paredes de Coura), Bruzendes (Linhares, Paredes de Coura), Eja (Penafiel), Genso (Couto, Refoios de Lima), Pedrosa (Trasestrada, Riós), Baldoeiro (Horta da Vilariça, Torre de Moncorvo), Florderrei (Arzádigos Villardevós), "Outeiro" (Gomariz, Baltar), "Monte de São Paulo (Poiares, Freixo de Espada à Cinta), "Alto do Castelo" (Frende, Baião), "Alto do Chacim" (Refojos de Basto, Cabeceiras de Basto), "Penedo do Caixão" (Serzedelo, Guimarães), y "Monte de Santo Ovidio" (Sta. Marina de Arcozelo, Ponte de Lima). mediados del s. VII d. C. en adelante con una función de "refugio". En este caso, la reocupación de antiguos castros no tendría nada que ver con la existencia de algún tipo de jerarquización territorial, ni tan siquiera con la presencia de estructuras fortificadas, y mucho menos con su carácter militar, sino con factores endógenos inherentes a la propia evolución del poblamiento rural tardo-romano en tanto que hábitat de altura.

En una primera constatación a nivel espacial, y haciendo abstracción de la consabida aleatoriedad de los hallazgos, se trata de un fenómeno que afectaría a todo el territorio entre el Miño y el Duero (LÓPEZ QUIROGA-RODRÍGUEZ LOVELLE, e. p.; FERNÁNDEZ MIER; MARTÍN VISO; GUTIÉRREZ GONZÁLEZ). A continuación, una precisión, tanto a nivel espacial como en el plano temporal: los castros reocupados a partir de mediados del siglo VII d. C. se corresponderían, en general, con determinadas áreas que presentan unas características orográficas concretas: son espacios de montaña (Serra do Marão, Serra do Gerês, Sierra de Larouco). Por lo tanto, una primera observación: la reocupación de antiguos castros desde mediados del s. VII d. C. no obedecería a los mismos factores ni poseería la misma significación que las ocupaciones y reocupaciones de los dos siglos anteriores. $\mathrm{Su}$ origen sería necesario enmarcarlo en el contexto de las iniciativas de tipo fructuosiano que supondrían una "ampliación" de los espacios tradicionalmente ocupados, como son las áreas de valle próximas a la red viaria de época romana y a los núcleos principales y secundarios en torno a las mismas, en lo que constituiría un fenómeno generalizado de "expansión" y "agrupación" del poblamiento en áreas de altura (se trate de castros, de montes, de oteros rocosos o de simples colinas). Por lo tanto, estos asentamientos de altura que se desarrollarían desde la segunda mitad del s. VII d. C., no deberían ser calificados como "hábitat fortificados" (en la ausencia de elementos que apunten en esa dirección) sino, simplemente, como "hábitat de altura". En su origen, no habrían influido factores coyunturales de tipo externo, como sí ocurre con los castros que presentan ocupación en los dos siglos anteriores, sino que obedecerían a una serie de transformaciones estructurales propias a la dinámica evolutiva interna del poblamiento rural tardo-romano, por una parte, y a las transformaciones intrínsecas de la sociedad tardo-antigua peninsular, por otra (LÓPEZ QUIROGA, 2004; MARTÍN VISO; WICKHAM, 2005).

Por el contrario, el cambiante e inestable contexto socio-político, como consecuencia del proceso de configuración de las dos formaciones políticas 
dominantes (el reino suevo y el visigodo) que rigen los destinos de la Península Ibérica en la TardoAntigüedad, sí ha debido influir, como hemos visto, en los castros que presentan ocupación en los dos siglos anteriores. Así, a principios del s. V d. C., la situación de "incertidumbre" que crea la llegada de los "Suevos", dará lugar, como Hidacio señala, a que "una parte" de la población local galaico-romana se "organice" y "aglutine" torno a los castella tutiora y a los castra; entre ellos, algunos de los que hemos señalado para principios del s. V d. C. (como el castro de Saceda o el de Novás), que podrían haber adquirido, por razones geopolíticas evidentes, una función de tipo defensivo y simultáneamente una "posición jerárquica", difícil de calibrar con los datos actualmente disponibles, con respecto a los otros núcleos de poblamiento y, sobre todo, desde el punto de vista territorial. En este sentido, estos castra y castella, al menos durante el siglo $\mathrm{V}$ d. C., serían unidades de poblamiento menores respecto a la civitas de la que dependerían y en cuyo territorio se encontrarían ubicados. Servirían de punto intermedio, en lo que a ordenación y vertebración del territorio se refiere, entre las civitates y las otras unidades de poblamiento, fundamentalmente los uici y las uillae. Los habitantes de esos castra y/o castella estarían constituidos, a principios del s. V d. C., mayoritariamente por la propia población local galaico-romana, pero no por contingentes poblacionales foráneos. Con posterioridad, especialmente desde mediados del siglo VI d. C. en adelante, algunos de los castros con ocupación en esos momentos podrían haber servido de asiento a poblaciones no locales con una función asimilable a un carácter militar pero, sobre todo, como puestos de vigilancia sobre la red viaria (GARCÍA MORENO, 1987) o de control en pasos montañosos, en relación con el proceso de integración político-territorial de este espacio en el reino visigodo de Toledo desde la segunda mitad del s. VI d. C.; sean estas poblaciones visigodas, o simplemente asimilables a esa "agrupación étnica"10, aunque no descartamos la posibilidad de asentamientos similares con algún contingente poblacional perteneciente a la realeza militar sueva entre mediados del V y del VI d. C., como el castro novo, en la orilla derecha del Duero, actual Oporto; el castro da Curralha, al lado de

\footnotetext{
${ }^{10}$ Se da por generalmente admitida la existencia de una "masiva colonización del Noroeste por los Godos", tras la integración de este espacio hacia el 585 en el reino visigodo de Toledo. Ello se reflejaría en la toponimia y en la antroponimia de ascendencia "germánicas" (por ejemplo, en los prelados del siglo VII). (ORLANDIS, 1966; PIEL-KREMER; GARCÍA MORENO ; MATTOSO, 1992).
}

Chaves (TEIXEIRA, 1996); o el de Falperra, junto a Braga.

En definitiva, entre los siglos V y principios del VIII d. C., el castro constituiría un patrón de asentamiento fundamental cuyo significado no debería ser interpretado únicamente bajo el prisma de un hábitat "fortificado", sino como un asentamiento de altura poli-funcional que nos estaría indicando el dinamismo y las transformaciones que tienen lugar en el poblamiento rural tardo-antiguo del noroeste peninsular.

III. La presencia de una actividad comercial, fundamentalmente de importación, que no nos atreveríamos a calificar de "residual" sino en pleno auge y desarrollo durante una buena parte del período tardo-antiguo, es sintomática asimismo de la gran vitalidad y dinamismo que caracterizarían al conjunto de la fachada atlántica del noroeste peninsular. Este sector se circunscribe, en lo que respecta al territorio entre el Miño y el Duero, a la franja costera situada al Sur del río Cavado y el tramo navegable del Duero hasta la altura de Vila Real; área donde encontramos los lugares con importaciones de TSCD y $L R C$. Los núcleos donde hallamos estas cerámicas de importación no nos están indicando, precisamente, que estemos ante un "decaimiento" o "contracción" de la actividad comercial durante el período tardoantiguo (NAVEIRO LÓPEZ, 1991). Al contrario, ello constituiría un claro exponente de la intensidad de las importaciones que se mantendrían hasta bien avanzado el siglo VI d. C. ${ }^{11}$ y que, con las salvedades que se imponen, sería comparable al que simultáneamente se está produciendo en otras áreas costeras de la Península (GUTIÉRREZ LLORET, 1992) y a lo largo de todo el Mediterráneo (WICKHAM, 2005). Además, la importancia e intensidad de esta actividad de producción e intercambio podría no ser ajena, como hemos señalado, al fenómeno de ocupación o reocupación de antiguos asentamientos fortificados de altura tipo castro (denominados en las fuentes como castra y/o castella), que podrían estar asegurando el mantenimiento y sobre todo la protección de una actividad que nos atreveríamos a calificar como vital para la economía tardo-antigua del noroeste peninsular en lo que respecta al mantenimiento de una elite de raigambre tardo-romana que continua ejerciendo un papel preponderante.

IV. Las transformaciones morfológicas y funcionales en algunos sectores de las uillae y uici rurales, como

\footnotetext{
${ }^{11}$ 61. En el caso de la Toscana se detecta hacia el 650 el final de las importaciones cerámicas procedentesdel Mediterráneo oriental (WICKHAM, 1999, 10).
} 
consecuencia de los cambios aculturizadores que acompañan al proceso de cristianización y su progresiva expansión en el ámbito rural. Estos se detectan, fundamentalmente a través de la construcción de edificios de culto en el espacio de las uillae y de las transformaciones que se observan en la evolución de la topografía funeraria rural con el acercamiento progresivo de las inhumaciones en la iglesia $\mathrm{y}$, por lo tanto, de la configuración de los cementerios cristianos y la desaparición o abandono de las necrópolis paganas (LÓPEZ QUIROGARODRÍGUEZ LOVELLE, 1999).

En función de las informaciones disponibles, que, recordemos, no son homogéneas para el conjunto del territorio, podemos observar como el proceso de cristianización rural entre el Miño y el Duero, sin duda con ritmos e intensidades variables, presenta una dinámica evolutiva (en la que la práctica va siempre por delante de la legislación que la regula) durante el período tardo-antiguo en la que es posible distinguir:

*Un primer momento, entre el s. IV y mediados del VI d. C., profundamente marcado por el lento proceso de cristianización de las elites locales galaico-romanas en un contexto rural todavía fuertemente anclado en las prácticas paganas ${ }^{12}$. Es lo que se ha denominado, para otras áreas, como "la primera generación de iglesias rurales" (FOURNIER, 1982), caracterizada por la construcción de edificios de culto (oratorios o capillas) por parte de los propietarios de las uillae en un sector o extremo de las mismas, en lo que constituiría una forma de evergetismo rural (PIETRI, 1978; BROWN, 1961), dependiente en gran medida de la iniciativa privada de estas elites locales. Estas transformaciones no afectarían al carácter y significación de las uillae tardo-romanas como tales, pero sí a su morfología y composición interna, como hemos visto, ya que éstas se mantendrían como unidad poblacional característica durante este período. Para el conjunto del territorio entre Miño y Duero, y en función de la gran heterogeneidad de los datos disponibles, podemos observar la localización de edificios cultuales en el ámbito rural, tanto en castella, como en uici o en uillae. En las páginas precedentes hemos abordado el estudio de los edificios de culto

${ }^{12}$ Lo refleja a la altura del s. VI d. C. la legislación conciliar y, sobre todo, el De correctione rusticorum escrito por Martín de Braga como una "demonología" sobre los males y vicios que caracterizarían al medio rural del noroeste peninsular. (FERREIRO; Mc. KENNA, 1938). Sobre el problema del paganismo y sus permanencias en el medio rural en Occidente véase ahora HILLGARTH (ed.), 1992. construidos en los asentamientos de altura tipo castra o castella (como podría ser el caso del castro de Falperra, cerca de Braga) y en los de llanura, tipo uicus (cuyo paradigma podría ser el uicus de Aquis Quaerquennis, en Baños de Bande-Ourense, Fig. 4).

En lo que respecta a las uillae, encontramos edificios de culto, que podrían situarse en un arco cronológico entre el siglo IV y la primera mitad del VI d. C., sino en el entorno, al menos relativamente próximos de los dos núcleos urbanos principales existentes entre el Miño y el Duero para ese período: Braga y Chaves. En efecto, tanto en la zona interior del conventus bracarensis (caso de los lugares de San Verísimo de Ouvigo $^{13}$, San Salvador das Rozas ${ }^{14}$, Santa Marta de Lucenza $^{15}$ ) como en el área costera del mismo (en Santa Eulália de Aguas Santas ${ }^{16}$ o en Martim ${ }^{17}$,

${ }^{13}$ Ouvigo (en Blancos-Ourense, Fig. 9) constituye el único lugar para el que poseemos la certidumbre (como han puesto de manifiesto las excavaciones arqueológicas llevadas a cabo) de hallarnos ante un oratorio o capilla construido en un sector de la uilla pre-eexistente. La primera fase del oratorio (que se corresponde con la segunda etapa constructiva del edificio, cuya primera fase nos revela una construcción cuya funcionalidad cultual no está clara) se sitúa entre los siglos IV y V d. C., mientras que la segunda se enmarcaría en los siglos V y VI d. C. El principal cambio observado entre ambas fases es la aparición de una división interna en el edificio que separaría el espacio reservado al presbiterio, el del coro, el correspondiente a los hombres, a las mujeres y a los catecúmenos según RODRÍGUEZ COLMENERO, 1985.

${ }^{14}$ En la capilla de San Salvador das Rozas (en Medeiros, Monterrei-Ourense), es probable que nos hallemos también ante la presencia de una capilla u oratorio construido en un sector de la gran uilla que se intuye por la presencia de abundantes y significativos hallazgos en superficie (alineamientos de muros, abundante cerámica común y sigillata) (RODRÍGUEZ COLMENERO-LÓPEZ QUIROGA, 1991).

15 En la capilla de Santa Marta (Lucenza, CualedroOurense), las excavaciones arqueológicas han permitido exhumar algunos sectores de un gran establecimiento de llanura (de unas $12 \mathrm{Ha}$.) tipo uilla, cuya actividad se prolonga desde el siglo I d. C. hasta más allá del siglo IV, como parecerían indicarlo el epígrafe funerario de Vitalina (hallado a la entrada de la capilla) fechado en los siglos V-VI (RODRÍGUEZ COLMENERO, 1997, 349-350) e igualmente la cabeza de un christophorus, de cronología similar e incluso ampliable al siglo IV d. C. Aunque no se han hallado restos del probable edificio de culto construido en este sector de la uilla, es bastante plausible intuir su existencia debajo o en el entorno de la actual capilla de Santa Marta.

${ }^{16}$ En Santa Eulália de Aguas Santas (Río Covo, Barcelos), se hallaron diversos materiales de construcción al lado 
de la iglesia parroquial, entre los cuales habría TSCD (formas 97 y 104 de Hayes situadas en la primera mitad del s. VI d. C.), un pilar de altar paleocristiano (fechado en torno al s. V y VI) y una columna de mármol con paralelos estilísticos y decorativos norteafricanos. C. A. FERREIRA DE ALMEIDA, "Notas sobre a Alta Idade Media no noroeste de Portugal...", op.cit., 126 (nota 58); Ibid., "A propósito da Gallaecia sueva...", op.cit., p. 312; M. MARTINS, $O$ povoamento proto-histórico e a romanização..., op.cit., 736; J. ALARCÃO, Roman Portugal..., op.cit., 13 ( $n^{\circ} 229$ ). La función cultual de

este edificio no ha podido ser determinada con claridad, hablándose de la presencia de un complejo termal o de un edificio de culto. En nuestra opinión, no hay una contradicción entre ambas funcionalidades. En efecto, todavía a finales del s. VII d. C. se constata la operatividad de sistemas de calefacción tipo hipocausto, como narra la Vita Fructuosi que así ocurría en una de las habitaciones de una iglesia o monasterio, que era calentada por medio de este sistema durante la noche: "Quum enim intempestate noctis silentio omnes quiescerent, subito eidem hospitio ab ira furoris domini ueniens ignis succendit, quum intus habitaculo ignis ut adsolet minime haberetur". M. C. DÍAZ Y DÍAZ, La vida de San Fructuoso de Braga..., op.cit., 82-83 (nota 6). En el caso de Santa Eulália de Aguas Santas, es perfectamente plausible la presencia de un hipocausto que no entraría en contradicción con la existencia de un edificio de culto. Es más, la asociación entre sistemas de calefacción tipo hipocausto y edificios de culto, es un hecho relativamente frecuente en el noroeste. Ello se observa con claridad en la iglesia de San Bartolomé de Rebordanes (Tui), San Julián de Moraime (Muxía, A Coruña) o en la propia catedral de Santiago de Compostela. M. CHAMOSO LAMAS, "Noticia de las excavaciones arqueológicas...", op.cit., 275-231; Ibid., "Excavaciones arqueológicas en S. Julián de Moraime...", op.cit., 335-350; Ibid., "Excavaciones arqueológicas en la Iglesia y atrio de San Bartolomé de Rebordanes de Tuy...”, op.cit., 325333. Esta asociación entre ambos elementos no es más que una significativa muestra de la relación entre la construcción de los primeros edificios de culto cristianos sobre o a proximidad de los asentamientos de llanura tipo uillae y del aprovechamiento de las estructuras contractivas existentes adaptándolas a una función de tipo cultual en el contexto del proceso de cristianización del medio rural.

${ }^{17}$ En Martim (Barcelos), se plantea un problema similar al de Santa Eulália de Aguas Santas. En efecto, las excavaciones arqueológicas efectuadas al sureste de la iglesia parroquial de Martim han exhumado las fundaciones de un edificio en el que han sido reutilizadas piedras romanas. El material cerámico hallado se sitúa en los siglos V y VI d. C., sin embargo, la funcionalidad del edificio no está clara. Puede tratarse una vez más, de un edificio de culto construido en un sector de una uilla es probable, ambas en el término municipal de Barcelos), la presencia de estos edificios de culto (oratorios o capillas) o de restos significativos de los mismos, nos estarían señalando los canales a través de los cuales el cristianismo se introduciría en el medio rural: desde las "ciudades" hacia los otros núcleos de poblamiento que, situados en la proximidad de la red viaria, constituirían el exponente de una ocupación del espacio y una ordenación del territorio todavía fuertemente marcadas por la impronta romana (BONNET; FEVRIÈR; BERSCHEIN-GUENICHSTEUER, 2000; PERGOLA, ed., 1999).

Un tipo de edificio diferente de los señalados, pero cuyo origen se situaría en el ámbito cronológico que estamos tratando, es el constituido por los martyria. Para el período entre el siglo IV y la primera mitad del VI d. C., no se ha señalado hasta ahora ningún edificio de este tipo en el noroeste peninsular. No obstante, propondremos aquí un carácter y funcionalidad como martyrium para el complejo subterráneo existente bajo la fábrica gótica de la antigua iglesia de Santa Marina de Aguas Santas excavaciones efectuadas en este lugar a mediados del siglo pasado $^{18}$ no han aclarado el carácter y funcionalidad de dicho complejo cultual y, sobre todo, si la cripta es contemporánea o no del edificio gótico bajo el que se encuentra. Intentemos describir, en primer lugar, como se configura esta singular y excepcional cripta. Una vez que se descienden las escaleras que dan acceso a la misma, observamos en el centro del complejo la presencia de un gran sarcófago, del que sólo se conserva la base, alrededor del cual se disponen: por una parte, una serie de inhumaciones de las que se conservarían algunas laudas sepulcrales con signos diversos y, entre ellas, una con la representación del orante (sobre la que posteriormente fue tallada una cruz gótica de tipo procesional $\mathrm{y}$, por lo tanto, reutilizada en un momento contemporáneo al de la inacabada iglesia que hemos mencionado); por otra parte, un sistema de canalización de agua procedente del exterior de la cripta, que rodea por ambos lados el gran sarcófago ubicado en el centro de la misma. Un espacio rectangular, a modo de piscina, se sitúa en el ábside de la cripta y, frente a éste y en el otro extremo de la misma, hay un altar, bajo el cual continua la

aunque sólo nuevas excavaciones orientadas en esa dirección permitirían dar respuesta a ese interrogante (FERREIRA DE ALMEIDA, 1972, 219-326).

${ }^{18}$ Independientemente de que pudiese haber existido para esta construcción una fase más antigua que parecería identificarse, según Conde Valvís, con un monumento tipo "pedra formosa". Sobre este tipo de complejos y su carácter más medicinal que ritual, véase ACUÑA CASTROVIEJO, 1996, 45-47. 
canalización hacia el exterior del complejo. Por último, en el centro del ábside de la cripta existe un orificio que comunica a su vez con el ábside de la iglesia gótica. No olvidemos, tampoco, la "tradición popular" que refiere el "martirio e inhumación" de Santa Marina en este lugar. Es sumamente arriesgado, con los datos tan fragmentarios de que disponemos, pasar de la descripción a la interpretación de este singular complejo cultual. Como ya hemos indicado, nos inclinamos, como hipótesis de trabajo, a considerar esta cripta como un martyrium, probablemente existente ya en el siglo IV d. C., que habría dado lugar al desarrollo de un tipo de inhumación ad sanctos. De confirmarse esta hipótesis, se trataría de un edificio sepulcral dedicado al culto de una mártir local, Santa Marina en este caso, en el que tanto la canalización como las inhumaciones que rodean al sarcófago central, tendrían una significación de alto contenido simbólico, en el sentido que señala L. Pietri, al subrayar cómo la intervención del Santo a través de los cuerpos de los otros difuntos necesita la proximidad en el espacio entre ambas inhumaciones "car la virtus agissante du saint est conçue comme une sorte de fluide qui émane de son corps ou de ses reliques, se répend dans toute le sanctuaire, en imprègne les murs et le sol et infuse aussi la terre autour de l'édifice"(PIETRI). En nuestra opinión, la distribución topográfica que observamos en el complejo cultual de Santa Marina de Aguas Santas, obedecería a la descripción hecha por Gregorio de Tours y recogida por L. Pietri.

*Un segundo momento, entre mediados del siglo VI y del VII d. C., que supondría el triunfo cuasi definitivo del cristianismo de tipo ortodoxo en el medio rural, la instauración de una jerarquía elemental, juntamente con una estructuración y vertebración eclesiástica básica y más o menos homogénea del territorio. Se ha considerado esta etapa tradicionalmente como la de una "segunda generación de iglesias rurales" (FOURNIER, 1982), fuertemente vinculada con la actividad evangelizadora de algunos personajes de gran relevancia, tanto en el plano socio-religioso como político $^{19}$.

Es el caso, para el noroeste peninsular, de Martín de Braga $^{20}$, obispo de dicha ciudad y simultáneamente

${ }^{19}$ A Martín de Braga se le atribuye la conversión de los Suevos al catolicismo. Sobre la significación religiosa y política de este hecho, véase ahora GARCÍA MORENO, 1997, 199-216.

20 Originario de Panonia (circa 510-580), fundador de numerosos cenobios y, entre ellos, el suburbano de Dumio, en un movimiento de marcado carácter "abad-obispo" del monasterio suburbano de Dumio, ubicado en las afueras de la aglomeración bracarense. Para este momento, sería posible hablar de una intensa actividad constructiva de edificios de culto que darían lugar a una multiplicación de las iglesias rurales, configurando una organización eclesiástica del territorio mucho más homogénea y dotada también de un marco jurídico más estricto e inequívocamente ortodoxo. Ello no excluiría la presencia de amplias áreas (toda la actual región de Tras-os-Montes y el Alto Douro, juntamente con la parte oriental montañosa de la actual provincia de Ourense) en las que no se constataría, para estos momentos, la presencia de edificios de culto. Esto nos estaría indicando, lo que ya hemos señalado en varias ocasiones, como la región occidental costera del antiguo conventus bracarensis presentaría una organización y una estructuración, desde el punto de vista de la administración eclesiástica del territorio, mucho más homogénea y desarrollada que la parte oriental montañosa de dicha circunscripción administrativa. El documento conocido como Parroquial Suevo reflejaría lo que acabamos de decir y ello se correspondería, además, con la distribución espacial de los edificios de culto correspondientes a este período entre mediados del siglo VI y mediados del VII d. C. En efecto, son las áreas de valle en relación con la red hidrográfica y viaria en torno a Braga (antigua capital del conventus, obispado metropolitano de la Gallaecia, además de sede episcopal de Martín de Braga) y, no ya tanto de Chaves sino de Ourense (obispado que se crea precisamente en la segunda mitad del siglo VI), donde hallamos una relativa densa red de iglesias ${ }^{21}$, especialmente en torno a Braga, a lo que no es ajena la presencia de su obispo Martín y su intensa actividad evangelizadora. Por lo tanto, podemos

misional de tipo evangelizador. Su obra fundamental está recogida en C. W. BARLOW, Martín episcopi Bracarensis Opera Omnia..., op.cit.

${ }^{21}$ San Martiño de Pazó (Allariz), Feira Nova (Sta. María de Ferreiros, Amares), Giela (Arcos de Valdevez), Sta. Leocádia de Bairral (Baião), Sta. Comba de Bande (Bande), Sua Torre de Ambía (S. Esteban de Ambía, Baños de Molgas), Areias de Vilar (Barcelos), Sta. Mariña de Galegos (Barcelos), Monasterio de Banho (Vila Cova, Barcelos), S. Jerónimo de Real (Braga), Convento de Tibães (Braga), Cabreiros (Braga), S. Julián de Camba (Castro Caldelas), Sta. Leocádia de Briteiros, Convento da Costa (Guimarães), Ronfe (Guimarães), San Torcato (Guimarães), Sta. Cruz de Lima (Ponte de Lima), Souto (Terras de Bouro), Alvarães (Viana do Castelo), Monasterio de Vila Mou (Viana do Castelo), S. Mamede de Escariz (Vila Verde) y Duas Igrejas (Vila Verde). 
suponer que una gran parte, sino la totalidad, de estas iglesias rurales mantendrían una dependencia directa respecto al obispo de la diócesis en la que estarían ubicadas, lo que vendría igualmente a corroborar la insistencia de la legislación conciliar en reclamar para el obispo la propiedad y gestión de esos edificios de culto ${ }^{22}$.

*Un tercer momento, a partir de mediados del siglo VII d. C., estaría marcado por el desarrollo de una organización religiosa de inspiración eremítica, en lo que constituiría una simbiosis entre ambientes socioreligiosos del noroeste europeo procedentes de Irlanda y norte-africanos en consonancia con la tradición cenobítica de los "Padres del Desierto" procedentes de Egipto. Este momento, supondría un acusado retroceso para el cristianismo digamos de tipo ortodoxo estructurado y jerarquizado alrededor de la institución episcopal y de la figura del obispo como vértice de la administración eclesiástica de un territorio dividido en diócesis, frente a otro más heterodoxo y más ecléctico, dando así lugar al desarrollo de un cierto tipo de "monacato" que, precisamente en función de esos elementos constituyentes culturalmente tan heterogéneos, cristalizaría en una organización religiosa atípica con un fuerte contenido socio-económico (DÍAZ MARTÍNEZ, 1987; FRIGHETTO, 1997) e incluso, como veremos, político. Para el espacio miñotoduriense, y para amplias áreas del noroeste y norte peninsular, este proceso será impulsado y desarrollado con especial intensidad por Fructuoso de Braga $^{23}$. El monacato del noroeste y norte

22 Tanto el canon V y VI del II Concilio de Braga (572) como el canon XIX del III Concilio de Toledo (585). J. VIVES, Concilios visigóticos e hispano-romanos..., op.cit., 83 y 131.

23 Personaje extraordinariamente carismático. Su nacimiento tiene lugar a principios del s.VII y su muerte en torno al 665. Nacido en un ambiente aristocrático (su familia tiene amplias posesiones territoriales, son originarios de la Septimania, su padre pudo haber sido dux de la Gallaecia, pertenecen a la nobleza goda y probablemente hayan apoyado la revuelta de Sisnando -también originario de Septimania-). Fructuoso es iniciado en la tradición monástica por el obispo Conancio de Palencia. Funda a continuación el monasterio de Compludo, el de San Pedro de Montes y el de San Félix de Visonia (en la región del Bierzo, quizás en tierras heredadas de su padres). En Galicia desarrolla una intensa actividad en particular en las islas de la ría de Pontevedra y de Vigo, luego en Andalucía (fundación del monasterio de nono en la isla gaditana). Es nombrado, contra su voluntad, obispo metropolitano de Braga hacia el 656, lugar a partir del que promueve la fundación de otros monasterios en Galicia y Norte de Portugal. Es peninsular era visto en los ambientes religiosos ortodoxos como un movimiento al margen de las estructuras eclesiásticas de tipo jerárquico ${ }^{24}$ y sospechosamente heterodoxo a causa de su pasado priscilianista (LINAGE CONDE, 1973). El desarrollo del monacato en este espacio no es evidentemente un fenómeno "nuevo" en la segunda mitad del s. VII. Formas incipientes del mismo, se conocen desde finales del s. V d. C. (nombres como Baquiario o Eteria están vinculados a estos ambientes cenobíticos), aunque su gran impulso tiene lugar en el siglo VI (ligado a personajes como Juan de Biclaro, Eutropio de Valencia e incluso Martín de Braga, abad-obispo de Dumio). La "novedad" del movimiento monástico de inspiración fructuosiana radicaría en su acusado carácter "marginal" y "periférico". Marginal, porque estos pseudo monasterios (ya que, en general, no se trata de verdaderos cenobios strictu sensu $)^{25}$ se situarían al

enterrado en Montelios, al lado de Braga. La Regula monachorum y la Regula Communis son recogidas en la Patrologia Latina. Su vida es narrada por un autor anónimo, originario probablemente del área en torno a Braga, discípulo de Fructuoso (no necesariamente un monje) entre el 670 y el 680. El texto que se conserva, procede de un manuscrito de la Biblioteca

de León fechado en 902. La mejor edición es la de M. C. DÍAZ Y DÍAZ, La vida de S.Fructuoso de Braga..., op.cit. Sobre el movimiento monástico fructuosiano J. ORLANDIS, "Las congregaciones monásticas en la tradición suevo-gótica", Anuario de Estudios Medievales I (1964), p. 97-119; Ibid., "El movimiento ascético de S. Fructuoso y la congregación monástica Dumiense", en Actas del XIII Centenário da morte de São Frutuoso, vol. II, Braga, 1968, 81-91; Ibid., Estudios sobre las instituciones monásticas medievales..., op.cit.

24 Además, la Gallaecia era considerada de forma individualizada en el conjunto de las "Españas" por parte del poder central, tanto en el plano religioso como político. Un ejemplo de ello, para finales del s. VII d. C., lo constituye el XI Concilio de Toledo que se celebra sin la presencia de los prelados de la Gallaecia, al reunirse separadamente y con autorización de Wamba, en Braga (III Concilio de Braga). Es con ocasión de este concilio, precisamente, y bajo la presidencia del prelado bracarense y con la presencia de los de Tui, Oporto, Astorga, Britonia, Ourense, Lugo e Iria, cuando se acometerá la supresión "definitiva" de las prácticas litúrgicas heterodoxas tan características en el ámbito rural del noroeste peninsular.

${ }^{25}$ La Regula Communis critica este tipo de agrupaciones pseudo-monásticas y, paradójicamente, "facilita" su expansión. Sobre este texto A. LINAGE CONDE, "En torno a la Regula Monachorum y sus relaciones con otras Reglas monásticas", Bracara Augusta XXI (1967), 123-163; J. ORLANDIS, "El movimiento 
margen del "sistema", entendiendo por tal, no sólo la organización socio-religiosa de tipo ortodoxo marcadamente jerárquica (la que es legislada en los textos conciliares), sino también especialmente todo lo que concierne a la estructura socio-política y económica que sustenta el Estado visigodo de Toledo.

El enorme atractivo que para una gran parte de la población supone la organización pseudo-monástica fructuosiana, con evidentes ventajas económicas y sociales $^{26}$, al estar los miembros de estas comunidades pseudo-cenobíticas libres de prestar el "servicio militar" y, por lo tanto, exentos del pago del impuesto ${ }^{27}$, además de un "igualitarismo" entre sus componentes $^{28}$, totalmente ajeno y ausente en las uillae y otros asentamientos similares ${ }^{29}$, daría lugar a una masiva "huída" de los habitantes de las uillae

ascético de S. Fructuoso y la congregación monástica dumiense", en Estudios sobre las instituciones monásticas medievales, Pamplona, 1971, 69-82.G.

${ }^{26}$ Como subraya Díaz y Díaz, la actitud de Fructuoso se opone al típico modus vivendi romano, puesto que la creación de monasterios trae como consecuencia que esclavos y libertos cambien su estatuto social al entrar a formar parte de estos pseudo-monasterios, ya que, como decimos, no se puede hablar propiamente de monjes. DÍAZ Y DÍAZ, La vida de San Fructuoso de Braga..., op.cit., 85 (nota 4).

27. En la propia Vita Fructuosi, se recoge la prohibición por parte del monarca visigodo a los laicos que habitan en el noroeste peninsular, de hacerse "monjes", puesto que ello suponía una forma de "huída" de la obligación de realizar el servicio militar, es decir, de escapar a la imposición fiscal, lo que va contra la esencia misma del Estado: "Nisi et duces exercitus prouinciae illius uel circumseptus undique confinibus regi clamassent ut aliquantum proiberetur, -quia si fas fuerit permissionis non esset qui in expeditione publica proficisceretur- innumerabilis se debuit congregare exercitus monacorum", Ibid., op.cit. Ello sería indicativo del "peligro" real que suponían estas fundaciones pseudo-monásticas para el Estado visigodo.

${ }^{28}$ No solamente esclavos o libertos, sino también gentes procedentes de estratos sociales más elevados: "Rumore eximiae sanctitatis enixius crebrescente, multas idoneas ac nobiles personas, etiam ex palatio, seruitium regis relinquentes ad eius sacratissiman sitienter confugerunt disciplinam". Ibid., op.cit., 90.

${ }^{29}$ Igualitarismo entre categorías sociales, sexos y edades que da lugar rápidamente a la creación de comunidades pseudo-religiosas mixtas: "Tanta itaque in utroque sexu almifica florebat sanctitas atque eximia crescebat fama perfectionum ut uiri cum filiis suis ad sanctam se conuerterent congregationem monachorum, matronas uero eorum cum filiabus suis sancto se sociarent consortio puellarum", Ibid., op.cit. hacia esos centros ${ }^{30}$, con la consiguiente "inquietud" del Estado por el riesgo de desestructuración del "sistema" que ello suponía ${ }^{31}$. El paisaje montañoso característico del Norte y noroeste peninsular ${ }^{32}$ habría favorecido este carácter de "marginalidad" del movimiento monástico fructuosiano, al desarrollarse en áreas "periféricas" (el norte y noroeste peninsular $\mathrm{y}$, dentro del territorio entre el Miño y el Duero, en la "periferia" de los espacios de valle que rodean los núcleos episcopales y antiguos centros políticoadministrativos de época romana -como Braga y Chaves-) respecto al núcleo toledano donde reside el poder central visigodo. Por esta razón, entre otros factores de tipo socio-político inherentes a la propia evolución del Estado visigodo y a su acusado proceso de descomposición interna en la segunda mitad de la séptima centuria, tendría lugar en estas áreas "periféricas" "33 la configuración de una estructura

30 Por el enorme carisma de Fructuoso, que era considerado como un "modelo" de santidad y de virtud: "Tanti gloriosissimi et incomparabilis uiri rutilo fulgore radians exempla meritorum ita ardore fidei accendit animos populorum ut cateruatim undique concurrens agmina conuersorum inmensus fieret chorus", Ibid., op.cit.

31 Sintomáticas de la "crisis" del Estado visigodo, especialmente en la segunda mitad del s. VII, son, por ejemplo: el reinado de Chindasvinto, marcado por una opresión y extorsión generalizadas que llevaron a la ruina del Estado, como se refleja en los cánones del VIII Concilio de Toledo; la Ley de Wamba del 1 de Noviembre del 673, en la que el monarca imponía a todos los súbditos el servicio militar obligatorio; o la acusada fragmentación político-territorial que se agudiza irreversiblemente durante los reinados de Egica y Witiza, ya en el tránsito del s. VII al VIII. Sobre los momentos finales del reino visigodo de Toledo sigue siendo fundamental GARCÍA MORENO, 1975.

${ }^{32}$ Paisaje que aparece reiteradamente en la Vita Fructuosi, por ejemplo, en las fundaciones de monasterios: Compludo en el Bierzo:"loca nemorosa, argis densissima, aspera et fragosa per speluncas et rupes", Rufiana (identificado con San Pedro de Montes, también en el Bierzo): "remota solitudine in excelsorum montium sinibus" y Castroleón: "in abditissima solitudine in locum qui nuncupatur Castro Leonis". Estos paisajes son descritos como "abditissima heremi loca petit ac fronduosis secretisque nemoribus ita se occuli studuit ut nunc altissimis locis, nunc densissimus siluis, nunc etiam rupibus quae solis ibicibus peruiae sunt latebrando latitans ut non humanis sed diuinis oculis cemeretur". Ibid., op.cit., 86, 88, 92 у 93.

${ }^{33}$ A lo que no sería, ciertamente, ajena la existencia de una estructura social previa que supusiese un caldo de cultivo favorable a la expansión de este tipo de comunidades pseudo-monásticas. Esta estructura 
social pseudo-religiosa enormemente dinámica, que por sus consecuencias para el frágil equilibrio del "sistema" estaría dotada de un alto contenido y significación políticas ${ }^{34}$. El hecho de nombrar a Fructuoso obispo, contra su voluntad ${ }^{35}$, podría ser interpretado no sólo en clave religiosa sino, sobre todo, política, al ser una decisión que dejaría traslucir ese conflicto latente entre Fructuoso y el monarca visigodo durante toda la vida de aquél y que está presente en toda la narración del anónimo autor de la Vita Fructuosi.

Estas áreas "marginales" se convertirían así en el curso del s. VII, en "áreas centrales en la periferia", es decir, en espacios dotados de un gran dinamismo y una intensa actividad "creadora", que favorecería el desarrollo de una estructura social de corte pseudoreligioso con la "masiva", y en cierto modo anárquica, creación de comunidades monásticas, en muchas ocasiones compuestas por apenas algunas familias, de una organización socio-económica silvocinegético-pastoril ${ }^{37}$ y de una estructura poblacional en la que el patrón de asentamiento que la

social no se definiría por su carácter "gentilicio" (DÍAZ MARTÍNEZ, 1987, 191), puesto que tal tipo de organización no se verifica, sino por corresponder a poblaciones locales ubicadas en espacios en los que el binomio aculturizador, romanización-cristianización, habría sido menos intenso y eficaz que en otras áreas.

34 La prohibición del proyectado viaje de Fructuoso a Oriente por parte del monarca (DÍAZ Y DÍAZ, $L a$ vida de San Fructuoso de Braga..., op.cit., 112) constituye un hecho cargado de significación política, puesto que según la legislación visigoda (Código de Recesvinto, Libro IV, I, VIII), toda persona que saliese de la Península era considerada como un "traidor", potencial revolucionario y oponente político. Tanto el episodio narrado en la Vita Fructuosi, como sobre todo esa legislación. Constituyen un buen síntoma del ambiente de desconfianza en el que se movía el Estado visigodo a finales del s. VII d. C.

35 "Post haec uidelicet, licet inuitus, contra uoluntatem suam langoris merore depressus perniciter resistendo in sede metropolitana dono dei ordinatus est pontifex". Ibid., op.cit., 112.

36 "et quia rumor gloriosae sanctitatis eius cunctas peragrauerat regiones, quum ex multitudine diuersorum occurrentium crebram pateretur inquietudinem", Ibid., op.cit., 86.

${ }^{37}$ En áreas en las que esta actividad es característica, por ejemplo: el episodio que narra la infancia de Fructuoso con su padre en el Bierzo; o el del cazador que repentinamente encuentra a Fructuoso y lo confunde con un animal al estar cubierto con una piel de cabra; o el de la cabra perseguida por un grupo de cazadores que se refugia junto a Fructuoso... Ibid., op.cit., 82,86 y 94 . configuraría se definiría por su carácter "marginal" y "periférico".

Debemos preguntarnos, a continuación, si es posible identificar para el espacio entre el Miño y el Duero, áreas y lugares que pudiesen responder al proceso descrito, en general, para el norte y noroeste peninsular. En efecto, amplias áreas de este territorio podrían responder a una organización de inspiración fructuosiana: el bajo valle del Miño y Limia, los espacios de montaña en el tramo central del Miño y de la desembocadura del Sil, la desembocadura del Támega en torno a la Serra do Marão, alrededor de la Sierra de Larouco, y las zonas montañosas que rodean los valles de los ríos Tua y Sabor. Es decir, se trata de áreas "periféricas" respecto a los espacios donde residen las autoridades políticas y religiosas, las antiguas civitates de época romana, ahora transformadas en obispados, que también son áreas al "margen" de los circuitos comerciales especialmente activos e intensos en la franja costera situada entre el Câvado y el Duero. Por ello, se trataría de espacios proclives a la formación de células de poder autónomas, a nivel local o como mucho supra-local, políticamente invertebradas, quizás ya desde época prerromana $^{38}$, y que no logran consolidar una superestructura socio-política lo suficientemente fuerte como para imponerse sobre amplios conjuntos territoriales.

A pesar de la enorme dificultad que supone el trasladar a lugares concretos el fenómeno que estamos describiendo, debido a la parquedad de

38 Aunque, reconozcámoslo, nuestro conocimiento sobre la organización socio-política de las comunidades indígenas en los momentos previos a la integración de este espacio (y de todo el noroeste peninsular en general) es todavía insuficiente. En función de lo que se observa en ámbitos espaciales próximos (como en amplias zonas de la Meseta Norte), podemos suponer que en el noroeste la evolución no habría sido muy distinta (aunque existan igualmente diferentes puntos de partida entre ambas áreas) y que, por lo tanto, el grado de "complejidad" organizativa y desarrollo socio-político de estas comunidades locales fuese lo suficientemente importante como para que la interacción con el mundo romano y el proceso de aculturación al que se ven sometidas no supusiese ni un cambio ni una ruptura radicales sino, más bien, la culminación de un largo proceso evolutivo interno de las mismas. Dos puntos de vista sobre este proceso para el noroeste en DE LA PEÑA SANTOS, 1997, 143-193; CALO LOURIDO, 1997, 193-213; también ACUÑA CASTROVIEJO, para la Meseta Norte véase ahora GÓMEZ FRAILE, 2002 (con amplia bibliografía e interesantes y renovadores planteamientos sobre la cuestión). 
nuestras fuentes de información, poseemos algunos datos que podrían corresponderse con esta organización social pseudo-religiosa y con unos patrones de asentamiento que calificaremos como "fructuosianos":

- en el área comprendida entre los cursos finales del Miño y del Limia (en Sabariz -Vila Verde-, Láminas XLV y XLVI, en el castro de Vieito o en el de Roques, cerca de Viana do Castelo), existen una serie de grutas, tradicionalmente interpretadas como "eremíticas" (REAL et al, 1982), que habrían podido servir como lugares de habitación y espacios de culto para un conjunto de pequeñas comunidades con una organización socio-económica de inspiración fructuosiana. Se trata, también, de un área donde hallamos una relativa concentración de lugares con cementerios excavados en la roca (Figura 12).

- en las áreas de montaña del tramo medio del Miño y Sil, tenemos un lugar que podemos considerar paradigmáticamente representativo de este tipo de pseudo-monasterios mixtos en la más pura tradición fructuosiana. Nos referimos al complejo cultual de San Pedro de Rocas (Esgos, Ourense) (Fig. 13 y 14). Que no estamos ante un "monasterio" strictu sensu, y mucho menos ante una comunidad propiamente eremítica, es un hecho evidente: por una parte, el cementerio de tumbas excavadas en la roca (más de medio centenar de inhumaciones ${ }^{39}$ ) no deja lugar a dudas sobre la mezcla de sexos y edades en la población que componía esta comunidad (mujeres, hombres y hasta recién nacidos), compuesta por unidades familiares correspondientes a una población cuantitativamente importante que se desarrolla desde el s. VII, y cuyo período de máxima actividad se

39 Además de las inhumaciones que ya se conocían, las excavaciones efectuadas en 1988 permitieron exhumar un importante cementerio de tumbas excavadas en la roca (tipo bañera, ovales, trapezoidales $\mathrm{y}$ antropomorfas), cuyo origen se remontaría al siglo VII d. C. ORERO GRANDAL, "San Pedro de Rocas...", op.cit., 215-218. El casi medio centenar de tumbas no significa que estemos ante una población cuantitativamente equivalente, sino que dado que este tipo de inhumaciones son reutilizadas en múltiples ocasiones, es muy probable que el número de habitantes del lugar duplicase o triplicase al número de tumbas. Así se ha comprobado en otras áreas con este tipo de inhumaciones, como en San Vincenzo al Volturno, donde se han logrado identificar un total de 76 esqueletos para 30 tumbas excavadas, lo que equivaldría a una media de 2.53 individuos por tumba, estimando que habría unas 120 tumbas en el cementerio, ello daría una población total de unos 304 individuos. COUTTS, "The Hilltop Cemetery", en San Vincenzo al Volturno..., op.cit., 115. situaría en los siglos VIII y IX; por otra, los acondicionamientos realizados sobre las rocas (escaleras, conducciones de agua, encajes para vigas, huellas de sistemas rudimentarios de fortificación para vigilar y proteger el lugar, pilas de recogida de agua...), nos están indicando que estamos ante un núcleo habitacional que parece corresponderse con los "paisajes fructuosianos" y sus formas de organización características, en este caso de tipo rupestre. La inscripción "fundacional" que se conserva en el Museo Arqueológico Provincial de Ourense y el pie de altar "mozárabe" deberían situarse en el contexto de la "reestructuración" del lugar en torno al s. $\mathrm{X}^{40}$, tanto en el plano religioso, al entrar a formar parte de una estructura más ortodoxa, aunque de tipo monástico ${ }^{41}$, como socio-político, al perder esta comunidad su autonomía para integrarse en la formación política dominante que representa el reino astur-leonés. Es éste un mecanismo que se ha debido de repetir con relativa frecuencia desde finales del siglo IX en estas áreas "periféricas" y sobre estas comunidades locales políticamente desestructuradas y cuyo único elemento de cohesión sería su carácter pseudo-religioso en el marco de las iniciativas

${ }^{40}$ Una propuesta de cronología distinta para la inscripción (fechada a finales del s. VI) y el pie de altar (que sería de la misma época) en RODRÍGUEZ COLMENERO, 1997. El hecho de que dicha inscripción fuese, en efecto, de finales del s. VI, en nada invalidaría el análisis que proponemos sobre este complejo cultual $\mathrm{y}$, sobre todo, habitacional. No olvidemos que la inscripción habla de varios "fundadores" (por lo tanto no se trataría de un eremita aislado), probablemente acompañados de sus familias y bajo una forma de organización pseudo-monástica (en todo caso, más bien de tipo heterodoxo) que configuraría una comunidad en la que, sin duda, el elemento religioso sería el vínculo y elemento de cohesión fundamental.

${ }^{41}$ El documento "fundacional" del monasterio, en el siglo $\mathrm{X}$, hace naturalmente referencia a ese "pasado eremítico" que justificaría la integración de Rocas en una organización religiosa más ortodoxa. Es característico de los monasterios benedictinos el instalarse en lugares de tradición "eremítica". Sobre el monacato benedictino en Galicia véase ahora ANDRADE CERNADAS, El monacato benedictino $y$ la sociedad en la Galicia medieval..., op.cit. Sobre el significado de lo "movimiento eremítico" en la Alta Edad Media HEUCLIN, Aux origines monastiques de la Gaule du Nord..., op.cit. El proceso descrito para Rocas es similar al que tiene lugar también en San Vincenzo al Volturno y en otros núcleos monásticos italianos similares. C. WICKHAM, "Monastic lands and Monastic patrons", en San Vincenzo al Volturno..., op.cit., 138-152; también LINAGE CONDE, "El monacato visigodo. Hacia la benediztización", en Visigodos. Historia y civilización..., op.cit., 235-261. 
monásticas de tipo fructuosiano. San Pedro de Rocas (Fig. 13 y 14) es, sin duda, una comunidad aldeana configurada por una edilicia habitacional de tipo rupestre.

- en la desembocadura del Támega y en las estribaciones occidentales de la Serra do Marão, tenemos la pequeña capilla de Santa Leocádia de Barrial (FERREIRA DE ALMEIDA, 1975, 29-39). Las excavaciones arqueológicas efectuadas en el entorno de la misma han permitido exhumar un edificio de culto y un pequeño cementerio con tres etapas: la primera, correspondería a las inhumaciones de forma rectangular de tegulae (tumbas $\mathrm{n}^{\circ} 1,4$ y 5), que se situarían en los siglos V-VI ya que las fundaciones del edificio están sobre estas tumbas, con lo que aquél es posterior a éstas; la segunda, identificable a través de las inhumaciones en tierra (tumbas $\mathrm{n}^{\circ} 2,3$ y 7 ), que se sitúan en un nivel superior a las tumbas precedentes y, por lo tanto, son posteriores al siglo VI; la tercera, se relaciona con un conjunto de 3 o 4 tumbas excavadas en la roca existentes en un roquedo ubicado algunos metros por detrás de la actual capilla de Santa Leocádia, en el cual se observan rebajes y hendiduras para servir de asiento a una estructura de tipo lígneo. Este conjunto de tumbas se situaría a partir de mediados del siglo VII.

Tanto en San Pedro de Rocas, como en muchos otros lugares con este mismo tipo de inhumaciones asociadas a antiguos edificios de culto en parajes rocosos y generalmente de topografía elevada, estaríamos en presencia de pequeñas comunidades familiares de tipo aldeano, que parecerían responder a las características que hemos definido para la organización social pseudo religiosa de inspiración fructuosiana desde mediados del siglo VII, y que tendría sus momentos álgidos durante los siglos VIII y IX, al verse favorecida por un contexto sociopolítico en el noroeste peninsular caracterizado, precisamente, por la ausencia de estructuras de poder a nivel supra-local o regional capaces de aglutinar en torno a ellas a estas poblaciones locales "marginales" y "periféricas", en el sentido que hemos dado a estos dos términos.

En definitiva, mientras que entre los siglos IV y VI d. C. el proceso de cristianización habría dado lugar a una serie de transformaciones internas en el seno de las uillae tardo-romanas, sin que éstas desapareciesen como unidad de poblamiento y elemento omnipresente en el paisaje rural entre el Miño y el Duero; por el contrario, a partir del siglo VII d. C., el desarrollo de la organización pseudo-religiosa y socio-económica que acompañaría al movimiento "monástico" de inspiración fructuosiana, inscrito a su vez en un contexto de crisis $^{42}$ general a nivel europeo en el plano socio-político (afectando especialmente al Estado visigodo), supondría la quiebra definitiva de la tradicional ordenación del territorio, de las formas de ocupación del espacio y de las estructuras de poblamiento típicamente romanas. Al mismo tiempo, tendría lugar, desde el punto de vista de la ocupación del espacio y de la actividad socio-económica, una "ampliación", "conquista" o "revalorización" de áreas consideradas como "marginales" o "periféricas" (zonas de bosque o de montaña), que pasarían a ocupar un lugar central en el curso del siglo VII d. $\mathrm{C}^{43}$. Precisamente, la existencia de fuertes contrastes regionales, micro-regionales e incluso locales, tanto a nivel de poblamiento, como sobre todo en el plano de las estructuras socio-políticas, hace extremadamente difícil y particularmente arriesgado cualquier intento de generalización o de propuesta de modelos unívocos y simplificadores para un territorio tan vasto como el comprendido entre los ríos Miño y

${ }^{42}$ Favorecido por un contexto mental, característico del s. VII peninsular, sumamente receptivo a este tipo de ambientes apocalípticos, escatológicos y taumatúrgicos, de lo cual constituye un buen exponente la vida y la actividad de Fructuoso de Braga (así como la autobiografía de su discípulo Valerio del Bierzo). Existiría, por lo tanto, una "predisposición psicológica" (a la manera del "inconsciente colectivo" descrito por Jüng) de la población peninsular para el desarrollo de movimientos como el impulsado por Fructuoso. No olvidemos, además, que el III Concilio de Braga (675), contemporáneo al momento en el que se está redactando la Vita Fructuosi, legisla en contra de los suicidios colectivos que tienen lugar en el noroeste peninsular. Se trata, por otra parte, del primer canon de este tipo en toda la legislación conciliar de Occidente. Agradecemos al Prof. Michel Rouche el habernos advertido sobre este hecho y su probable conexión con el problema que aquí estamos tratando. Un panorama de las condiciones de vida del campesinado de este momento en GARCÍA MORENO, "El campesinado visigodo entre bajos rendimientos y catástrofes naturales. Su incidencia demográfica", en Visigodos. Historia y civilización..., op.cit., 171-189.

${ }^{43}$ En lo que el papel del monacato, ortodoxo o no, habría sido esencial: "Antes bien la puesta en cultivo de nuevos espacios se habría debido a dos causas fundamentales: a) variaciones concretas de la magnitud de determinadas familias campesinas; b) desplazamientos de grupos humanos hacia regiones hasta entonces no explotadas y marginales, por obra fundamentalmente de las nuevas fundaciones monásticas": GARCIA MORENO, "El campesinado visigodo entre bajos rendimientos y catástrofes naturales. Su incidencia demográfica”..., op.cit., 182. 
Duero. Además, todo ello debe de situarse en el marco de una progresiva acentuación de las diferencias entre las tradicionales áreas centrales, tales como el curso medio del Cávado, entre Sousa y Támega, el valle del alto Támega, el tramo medio y alto del Limia, la desembocadura del Duero, y las que se ubican en la periferia de aquéllas, como la Serra do Xerês, Serra do Marão, Sierra de Larouco y amplias áreas de Tras-os-Montes y Alto Douro, especialmente entre el Tua y el Duero, durante el todo el período tardo-antiguo y, sobre todo, a partir del siglo VII d. C., convirtiéndose así a partir de ese momento algunos de esos espacios periféricos en lo que hemos denominado como "áreas centrales en la periferia". Esta dialéctica centro-periferia, teniendo en cuenta las diferentes escalas de análisis espacial (local, supra-local, regional, supra-regional) y los amplios arcos temporales en los que nos movemos (entre el s. IV y el VIII d. C.) permite detectar y singularizar la dinámica y las transformaciones que caracterizarían la evolución del poblamiento rural tardo-antiguo en el noroeste peninsular.

Existe, pues, una gran complejidad (que impide todo intento de generalización y mucho menos de modelización) en las estructuras de poblamiento para la región miñoto-duriense, síntoma y consecuencia de la gran versatilidad, diversidad y dinamismo del poblamiento rural tardo-antiguo en dicho territorio. El peso de los factores externos de tipo aculturizador (el proceso de cristianización principalmente, pero también ciertos acontecimientos de tipo sociopolítico) han debido influir notablemente, sin que ello signifique caer en una explicación de tipo determinista, en la evolución y, sobre todo, en las transformaciones del poblamiento rural en la Gallaecia meridional ${ }^{44}$. En particular, los edificios de culto, desde su aparición en el siglo IV d. C., parecen haber tenido un papel morfogenético fundamental en la configuración del paisaje, del poblamiento y de la organización del territorio, comparable al que supuso en su momento el sistema de ocupación y explotación

${ }^{44}$ Por ejemplo, en el sud-oeste de Alemania, los antiguos Agri Decumates, la integración de este espacio en la órbita política del reino merovingio en el s. VI habría dado lugar a un cambio en los patrones de asentamiento, pasándose de los Höhensiedlungen (poblados de altura), característicos de los Alamanes durante los ss. IV-V, a las Reihengräberfelder (los cementerios de hileras), inhumaciones "típicas" del ámbito cultural merovingio. STEUER, "The hierarchy of Alamannic settlementts in the former limes region of south-western Germany to A. D. 500"..., op.cit., 8296. Una interpretación completamente diferente, en la que sería la conquista carolingia (s. VIII) la que conllevaría un cambio en los patrones de asentamiento, en SAMSON, 1994, 341-360. del territorio basado en las uillae o asentamientos rurales de llanura similares (VOLPE-FAVIAGIULIANI).

Sin embargo, y como hemos repetido de forma insistente, la propia dinámica interna evolutiva del poblamiento rural romano parecería ser el hilo conductor que canalizaría las transformaciones que sobre el mismo tendrán lugar entre los siglos $\mathrm{V}$ y VIII d. C., puesto que, como acertadamente señala Toubert, el proceso de cristianización acompaña y, sobre todo, sigue las fluctuaciones del poblamiento ${ }^{45}$.

El corolario de este complejo proceso será el "final" de las uillae (BROGIOLO; RIPOLL ARCE; LÓPEZ QUIROGA-RODRÍGUEZ MARTÍN; LÓPEZ QUIROGA, 2005; CHAVARRÍA) como forma de ocupación del espacio, como unidad de explotación socio-económica y como uno de los patrones de asentamiento característicos del paisaje rural tardoantiguo del noroeste y norte peninsular, lo cual tendría lugar a lo largo del s. VII en general, aunque con ritmos e intensidades distintos tanto a nivel regional como infra-regional e incluso local. Esta lenta "desaparición" de las villae no significaría que la "Antigüedad" culmine con ese proceso clave desde el punto de vista de la evolución de las estructuras socio-económicas y de poblamiento.

En este sentido, es lícito preguntarse si el surgimiento y desarrollo (como parte del proceso de cristianización rural) de esa organización social de tipo pseudo-religioso que son las comunidades monásticas de corte fructuosiano en amplias áreas del noroeste $\mathrm{y}$ norte peninsular $\mathrm{y}$, sobre todo, si las formas habitacionales y patrones de asentamiento que las caracterizan constituyen la última etapa del poblamiento rural tardo-antiguo o las primeras manifestaciones del poblamiento medieval (LÓPEZ QUIROGA, 2006). En nuestra opinión, estaríamos más bien asistiendo a los epígonos del poblamiento rural tardo-romano, en lo que al espacio entre Miño y Duero se refiere y para amplias áreas del noroeste y Norte peninsular. Quizás debamos entender ese vasto "movimiento del centro a la periferia", tanto a nivel local (en el seno de las villae) o supra-local (a nivel de un valle) como regional (en el territorio comprendido entre Miño y Duero) o supra-regional (en el ámbito del Noroeste y Norte peninsular), como una de las "últimas transformaciones" de las villae o asentamientos de llanura similares; puesto que, al fin y al cabo, esas áreas "marginales" y "periféricas" formaban parte del espacio de las uillae, compuestas

\footnotetext{
45 "la souplesse de la géographie religieuse du Haut Moyen Âge et son souci constant de suivre les fluctuations du peuplement" (TOUBERT, 1973, 855).
} 
por el ager y el saltus. Si bien es cierto que, durante un período de tiempo considerable, el ager habría ocupado una posición dominante respecto al saltus, podemos intuir que, fundamentalmente en el curso del s. VII y como consecuencia del proceso descrito anteriormente, el saltus pasaría a ocupar una posición central de la que hasta entonces habría carecido, rompiendo así el equilibrio del binomio ager/saltus en favor de esos espacios tradicionalmente considerados como "marginales" y "periféricos". Es posible también, que la "ruptura" en el curso del siglo VII de esa ecuación que sostenía el frágil equilibrio del sistema de ocupación del espacio y de explotación socio-económica típicamente romano a través de la auténtica "revolución" que supusieron las iniciativas pseudo-monásticas de tipo fructuosiano con su corolario de pequeños núcleos de habitación dotados de una "anárquica" pero efectiva organización social pseudo-religiosa, haya favorecido la permanencia de la población local en los mismos lugares (en un extremo de las uillae) o a unos metros de distancia de los mismos (en oteros rocosos, pequeñas colinas, antiguos castros o montes), los cuales siempre habrían sido ocupados o explotados desde época prerromana. Sin la permanencia de esa población local, que no sería posible calificar como "residual" pero que podría estar políticamente desestructurada, no se pueden explicar, ni sostener, ni entender el vasto proceso de reestructuración e integración del territorio, que tiene lugar entre Miño y Duero desde finales del s. IX en el seno de la formación socio-política que configura el reino asturleonés. Sería, a partir de este momento, con ritmos e intensidades distintos espacial y temporalmente, cuando tendría lugar realmente el "final de la Antigüedad" en el extremo meridional de la antigua Callaecia.

El estudio de la dinámica evolutiva del poblamiento rural entre comienzos del s. VIII y finales del X, lo que se viene considerando como período altomedieval, está marcado también por una serie de apriorismos historiográficos que han influido y todavía influyen (PORTELA-PALLARES, 1997) en los investigadores que se aproximan al estudio de este período a caballo entre la Antigüedad y lo que conocemos como Edad Media. No vamos a recordar aquí las etapas y avatares de este "apasionado" debate historiográfico sobre la supuesta "despoblación" y posterior "repoblación" de un valle del Duero considerado in extenso. Por otra parte, en el actual contexto historiográfico europeo, ya no es posible reconstruir la historia del poblamiento a partir del binomio "ruptura" / "continuidad" o "despoblación" /"repoblación", puesto que no es posible expresarse en términos absolutos, como si de una ciencia exacta se tratase, cuando hablamos del poblamiento tardo-antiguo y alto-medieval, que entre los siglos $\mathrm{V}$ y X se caracterizaría esencialmente por su plasticidad y su dinamismo.

En el vasto espacio del bajo valle del Duero miñotoduriense, situado en el extremo meridional de la antigua Callaecia, las transformaciones internas que hemos observado en la evolución del poblamiento rural tardo-romano y especialmente aquellas que se originan en el curso del s. VII, en el contexto de lo que hemos denominado como iniciativas pseudomonásticas de tipo fructuosiano, no sólo no se interrumpirían durante los siglos VIII-IX, sino que parecerían configurarse como uno de los elementos definitorios y característicos del hábitat rural de este conjunto territorial.

A lo largo de los siglos VIII y IX el dinamismo de ciertas áreas tradicionalmente "marginales" y "periféricas" respecto a los espacios "centrales" (aquellos que mostraban una organización y estructuración más desarrolladas, donde además residían y ejercían su autoridad los representantes del poder civil y religioso) dará lugar a dos fenómenos que constituyen las dos caras de una misma moneda:

* Por un lado, la culminación del lento pero progresivo proceso de desestructuración de los elementos característicos del poblamiento rural romano. Es un fenómeno que, como hemos visto, es posible detectar fundamentalmente desde la segunda mitad del s. VII en el contexto del movimiento pseudo-monástico de tipo fructuosiano. El elemento, o podríamos también decir el "fósil director", que nos permitiría percibir este proceso de desestructuración de las formas características del poblamiento rural tardo-romano (especialmente en lo que respecta al sistema de villae) no son, como así ocurre durante los siglos V y VI, las producciones cerámicas sino, sobre todo, la presencia de conjuntos más o menos numerosos de cementerios compuestos por tumbas excavadas en la roca fundamentalmente antropomorfas (Figura 12), que surgirían y se desarrollarían en un extremo de las uillae, en castros (tanto ocupados ininterrumpidamente como reocupados en ese momento), en oteros rocosos, en montes $u$ otros lugares de topografía significativamente elevada.

La amplitud del arco cronológico que se atribuye a este tipo de inhumaciones (entre los siglos VII y XI) no debe hacernos olvidar que su período de máxima utilización, para el noroeste peninsular, se situaría en los siglos VIII y IX, como igualmente se ha comprobado en otras áreas del Norte de la Península y de fuera de ella. Por otra parte, estos espacios funerarios nos estarían mostrando un tipo específico 
de poblamiento, por lo que la secuencia ocupacional de los mismos (de los cementerios y de los hábitat a los que están indisociablemente unidos) no sería posible abordarla a nivel regional y menos todavía supra-regional, sino que aquélla dependería de la permanencia del poblamiento, de la organización y de la ocupación del espacio que representan (cuyo período álgido se situaría, para el espacio miñotoduriense, durante los siglos VIII y IX). Es decir, la escala de análisis se debe limitar al ámbito local o micro-regional. En este sentido, la presencia "masiva", de este tipo de cementerios para el espacio entre Miño y Duero (Figura 12), nos estaría indicando un tipo de ocupación del espacio característico de los siglos VIII-IX y que constituyen una auténtica red de aldeas muchas de ellas configuradas por un tipo de hábitat rupestre.

Estos cementerios, que parecen estar siempre asociados a un edificio de culto, serían la huella visible en el paisaje de un hábitat y de un poblamiento que hoy en día ha desaparecido. No estaríamos, por lo tanto, en presencia de las antiguas áreas funerarias y espacios de culto de los núcleos de habitación actuales, más o menos próximos éstos a aquéllas, sino ante antiguos hábitat que corresponderían a una etapa "anterior" en la secuencia ocupacional de un determinado lugar.

El análisis espacial de estos cementerios (juntamente con los edificios de culto a los que suelen estar asociados) en su relación topográfica con los núcleos de habitación actuales (generalmente mencionados en la documentación alto-medieval entre los siglos XXII) plantea la hipótesis de un abandono de esos antiguos lugares (ocupados durante los siglos VIIVIII y IX) por otros más adecuados al "nuevo" contexto socio-político y económico característico de los siglos X-XII.

* Por otro lado, y como consecuencia del proceso descrito anteriormente, tendría lugar un segundo fenómeno, el desarrollo "masivo" en esas áreas y espacios anteriormente "marginales" y "periféricos", de un hábitat rupestre. El carácter estacional de este tipo de hábitat no ofrece lugar a dudas, puesto que la mayor parte de esos sitios parecen ser abandonados a lo largo de la Edad Media y, en muchos casos, probablemente desde finales del s. IX o durante el s. $X$. En no pocas ocasiones, la mención documental de una villa y / o de una ecclesia (entre los siglos X-XII) hace referencia a un núcleo de habitación ubicado a algunos metros de distancia de otro anterior, del cual sólo son visibles algunas tumbas excavadas en la roca, confirmándose la idea de que estamos ante un poblamiento no estructurado en un marco organizativo de poder supra-loca o regional. En consonancia con ese carácter de estacionalidad, las estructuras habitacionales parecen definirse por estar elaboradas con materiales ligeros, en los que la madera sería un elemento fundamental. Estas construcciones, por lo tanto, son detectables a partir de las huellas que esos componentes lígneos dejan en forma de huecos de poste o fondos de cabaña donde se encajarían las vigas o postes que soportarían un entramado arquitectónico ligero fácilmente. Es lo que se observa en el complejo pseudo-monástico de San Pedro de Rocas (Esgos) (Figura 13 y 14), o en el asentamiento de "As Pereas" (San Pedro de Trasalba, Amoeiro, Figura 15), un característico hábitat de "fondos de cabaña" en la proximidad inmediata de un asentamiento rural romano.

El macro-proceso de reestructuración del poblamiento, de reorganización socio-religiosa y de vertebración político-territorial que lleva a cabo el reino astur-leonés, y que culminará con la cristalización de las estructuras de tipo feudal en todo el ámbito territorial del Norte peninsular entre los siglos X y XII, se apoyaría, en lo que a la región miñoto-duriense respecta, en tres agentes cuyas ambiciones e intereses son, con la excepción de su objetivo común que es el ejercicio del poder sobre el espacio y los hombres que lo habitan, raramente coincidentes: nos referimos a los obispados de Ourense, Braga, Oporto y antiguos obispados como Chaves, los monasterios de Celanova y Guimarães y la aristocracia laica juntamente con las elites locales. Los instrumentos que permitirían llevar a cabo este macro-proceso se fundamentan igualmente en tres componentes esenciales, que son los que la documentación escrita alto-medieval desde finales del s. IX nos muestra en plena actividad para el territorio entre el Miño y el Duero:

*en el plano de la reestructuración del poblamiento a través de las villae, como forma mayoritaria de ocupación del espacio y de explotación socioeconómica del territorio. Es lo que la documentación escrita alto-medieval nos "revela" desde finales del s. IX, con ritmos e intensidades distintas en el tiempo y en el espacio. En apenas 15 años (entre el 865 y el 880), la "onda expansiva" que irradia la formación socio-política encarnada por el reino astur-leonés, anexionará el espacio al Sur del Miño y hasta el río Duero. Ahora bien, inicialmente este proceso se llevará a cabo con especial intensidad en determinadas áreas, pero no de forma homogénea en todo el vasto territorio miñoto-duriense:

- por una parte, entre el 865 y el 868 (bajo el reinado de Ordoño I), la actividad reestructuradota y reorganizadora se centrará en el espacio comprendido entre los ríos Miño y Limia. La anexión de la antigua 
Palla Aurea (Ourense) y la restauración de la sede episcopal auriense en el 865, marcarán el punto de arranque de un proceso que se realizará a partir de tres ejes fluviales principales: el tramo medio del Miño, el curso del Arroya y el del alto Limia.

-por otra parte, entre el 868 y el 880 (con Alfonso III), las áreas que son objeto preferente de este vasto proceso reorganizador, cuyo detonante es la anexión de la Portum Cale romana y del Castrum Novum (el actual Oporto) sito en la margen derecha del Duero, juntamente con la restauración de la sede portuense, giran en torno a siete conjuntos espaciales que configuran las áreas de valle próximas a los obispados y las grandes entidades monásticas: por un lado, el trinomio que constituye el eje PortoGuimarães- Braga (los amplios espacios de valle en torno a la sede bracarense, el territorio vimaranense alrededor del monasterio de Guimarães y las áreas de valle próximas a Oporto); por otro, el eje ChavesVerín-Laroá (el alto valle del Támega y la meseta del alto Limia).

Es decir, se trata de aquellos espacios (la parte occidental costera del antiguo conventus bracarensis juntamente con áreas de valle puntuales en el interior del mismo) que a mediados del s. VI ya presentaban una organización y una estructuración muy acusadas y que, ahora, en el contexto de este vasto proceso de reordenación y reestructuración territorial que tiene lugar desde finales del s. IX, serán de nuevo objeto de una intensa actividad que les devolverá su función central y de núcleos donde residen las autoridades civiles y religiosas (Oporto, Guimarães, Braga, Ourense, Celanova y Chaves) que llevarán a cabo el proceso de señorialización que culmina con la implantación de las estructuras de tipo feudal entre los siglos X-XII.

Al margen de este proceso y en los momentos iniciales del mismo (al menos durante los siglos IX y $\mathrm{X})$ quedan amplios espacios $\mathrm{y}$ áreas fundamentalmente montañosas (Serra do Gerêz, Serra do Marão, Serra do Larouco, casi todo el Trasos-Montes y Alto Douro), en las que se mantendría una ocupación del espacio y una organización socioeconómica todavía características del poblamiento rural tardo-romano, del cual constituirían sus epígonos. Estas áreas tendrían ahora, sin embargo, un carácter "marginal" respecto al binomio constituido por las uillas y las ecclesiae -marco espacial y referente socioeconómico sobre el que se apoya el proceso de señorialización-y "periférico" en relación a las áreas nucleares donde reside y ejerce su autoridad el poder central.

*En lo que respecta a la reorganización socioreligiosa, las ecclesiae serán el elemento morfogenético en torno al que se organizan las unidades de habitación, hacia el que convergen y alrededor del cual se aglutinan las necesidades espirituales de la comunidad y los espacios de uso funerario. Los antiguos obispados (Braga, Oporto y Ourense) y las entidades monásticas de gran importancia (como el monasterio de Guimarães y el de Celanova) serán los polos vertebradores en torno a los cuales girará un proceso de restauración y reconstrucción de antiguos centros de culto juntamente con la edificación de otros nuevos, en lo que constituirá la última y cuasi definitiva etapa de configuración de la red parroquial rural entre los siglos IX y XII.

Esta "última generación" de iglesias rurales no parece basarse tanto en una "conquista" de espacios vírgenes través de la creación de "nuevos" edificios de culto, sino que más bien se explicaría por la existencia previa de una importante red de iglesias, dibujando así una densa malla que configura a su vez la insólita imagen ofrecida por el Censual de Braga para el espacio comprendido entre los ríos Limia y Ave (ámbito espacial de la diócesis bracarense); !Un total de 573 iglesias y monasterios literalmente apiñados entre el bajo valle del Limia y Ave! El Censual cumpliría aquí una importante función como instrumento que permite el ejercicio del poder sobre los centros de culto existentes, mediante la cuantificación y el control de los mismos, por parte de la administración eclesiástica, al mismo tiempo que se convierte en un instrumento de gestión económica, más o menos eficaz, en el marco del proceso de señorialización del espacio entre Limia y Ave. Por otra parte, la imagen que a finales del s. IX nos ofrece el Censual, nos muestra el nivel de colmatación ocupacional al que en ese momento se llega en los espacios de valle (en este caso en torno al obispado de Braga), lo que a su vez constituiría un estímulo y al mismo tiempo la causa de la extensión del proceso de señorialización a las áreas de montaña (las estribaciones meridionales y occidentales de los sistemas montañosos de Leboreiro, Gerês y Cabreira), que durante los siglos IX-XI se habrían mantenido al margen de ese proceso.

Lo que podemos observar en el espacio entre el Limia y el Ave, gracias a una privilegiada documentación excepcionalmente rica y generosa, es posible inducirlo para otras áreas como, por ejemplo, en torno al monasterio de Guimarães, de Celanova, la sede episcopal auriense y la de Oporto. Aquí, también, la restauración de la red eclesiástica se iniciaría desde finales del s. IX en las áreas de valle que dibujan los cursos fluviales principales (Miño, tramo final del Sil, Arnoya, Vizela, Leza, alto Támega, bajo Limia y tramo final del Duero) y en el 
curso de los siglos XI-XIII alcanzaría los espacios de montaña que las circundan, una vez completada la configuración de la red parroquial rural.

Pero, sin embargo, no debemos olvidar que el proceso iniciado en la segunda mitad del s. VII, en el marco de las iniciativas de tipo fructuosiano, habría permitido la "ampliación" de las áreas de poblamiento y la configuración de una verdadera constelación de aldeas hacia espacios considerados "periféricos" y "marginales". Sin este proceso crucial, que se prolongaría durante los siglos VIII-IX, no es posible, en nuestra opinión, explicar la intensidad y densidad de la red eclesiástica rural en el siglo XI. Ello permitiría, además, explicar por qué la hagiotoponimia se habría mantenido durante esos "oscuros" siglos VIII-IX en el sector meridional de la antigua Gallaecia.

*Por último, la vertebración socio-política del territorio. Ésta, como manifestación del ejercicio del poder sobre el mismo, tendría como máximo exponente lo que la documentación escrita altomedieval denomina ambiguamente castra y castella; es decir, una serie de fortificaciones que serían el resultado de un proceso de territorialización de las estructuras de poder a nivel local y supra-local. Ello constituiría un claro exponente de la plasmación física sobre el espacio (especialmente sobre aquéllos que constituyen los "laboratorios" iniciales del proceso de señorialización) del ejercicio del poder y de la diferenciación social inherente a las estructuras de tipo feudal. Las fortificaciones, los castra y castella, serían un referente a la vez simbólico y real del control del territorio y del dominio sobre los habitantes del mismo, el cual sólo es comprensible y explicable como un elemento más que integraría la red de poblamiento rural que desde finales del s. IX configuran progresivamente las uillae y las ecclesiae entre Miño y Duero. 
MAPA 1

EL MARCO GEOGRÁFICO

A. Situación del territorio entre el Miño y el

Duero en relación al conjunto de la Península Ibérica

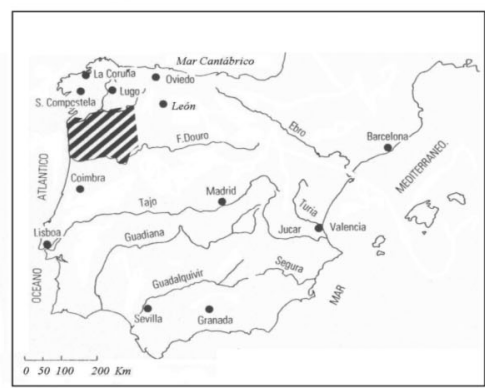

B. Referencias geográficas para el conjunto del espacio:

red hidrográfica, orográfica y localidades principales

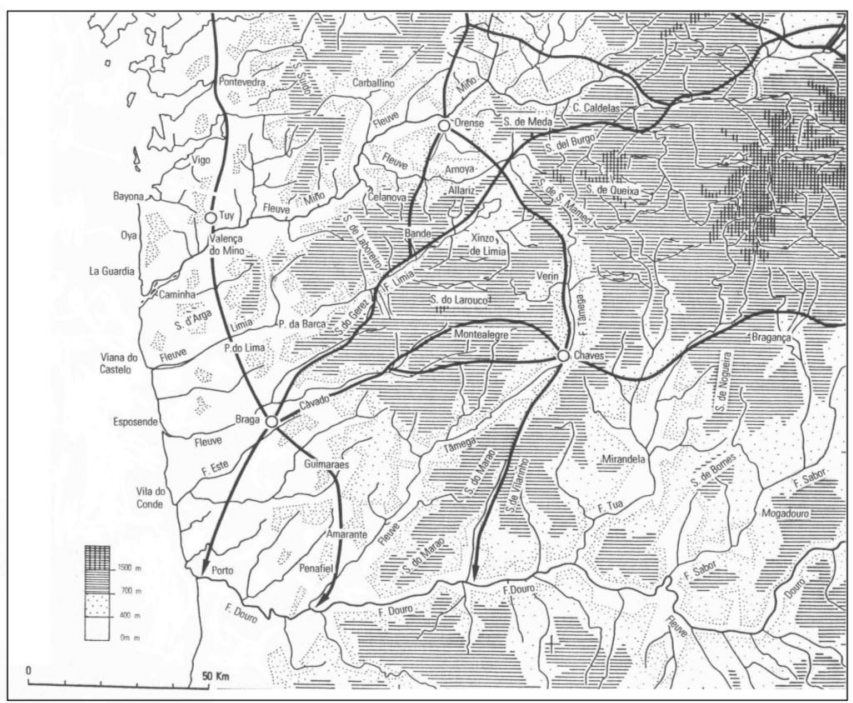

Fig. 1. El territorio entre el Miño y el Duero (LÓPEZ QUIROGA, 2004).

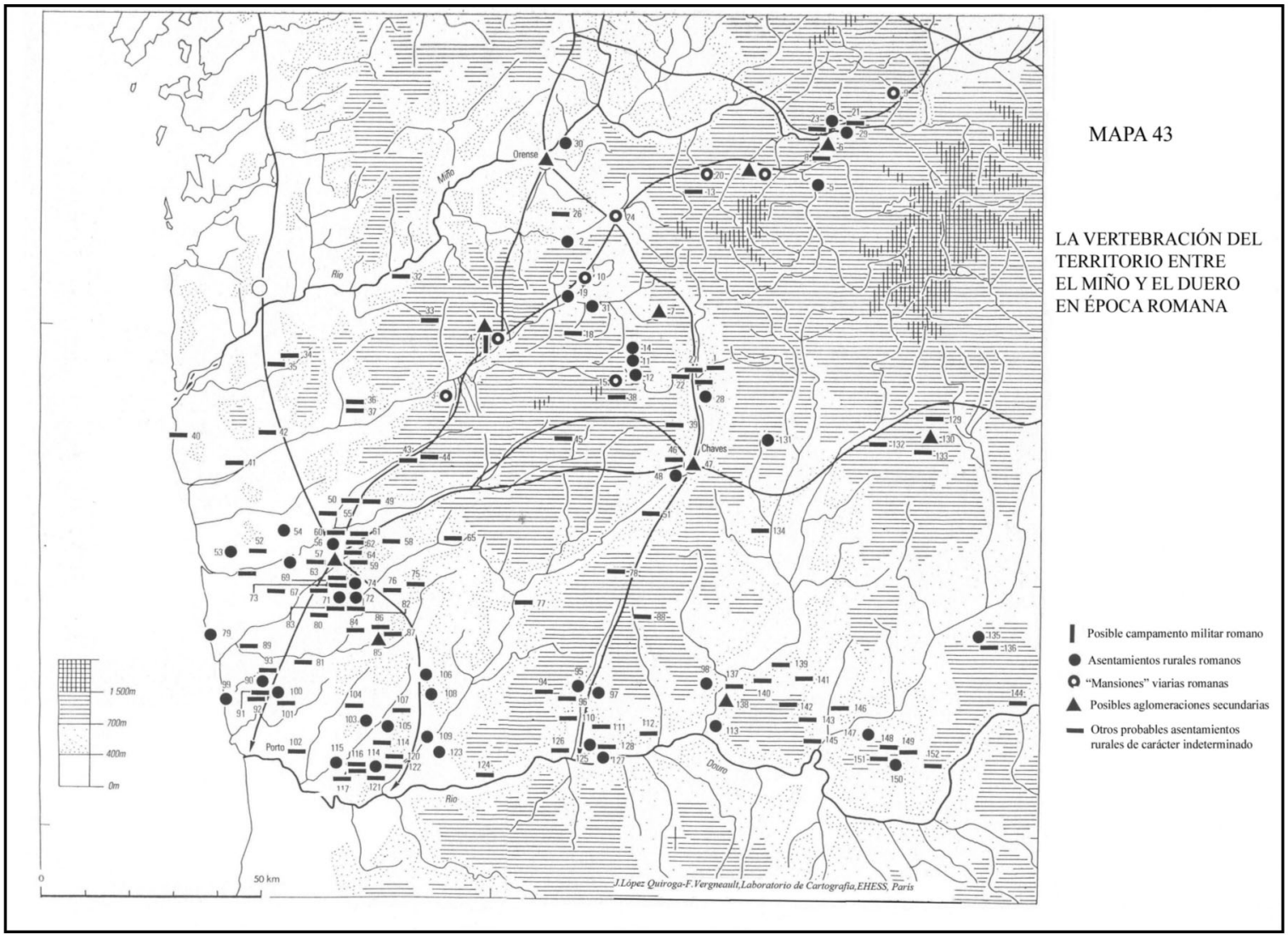

Fig. 2. El poblamiento romano entre el Miño y el Duero (LÓPEZ QUIROGA, 2004). 


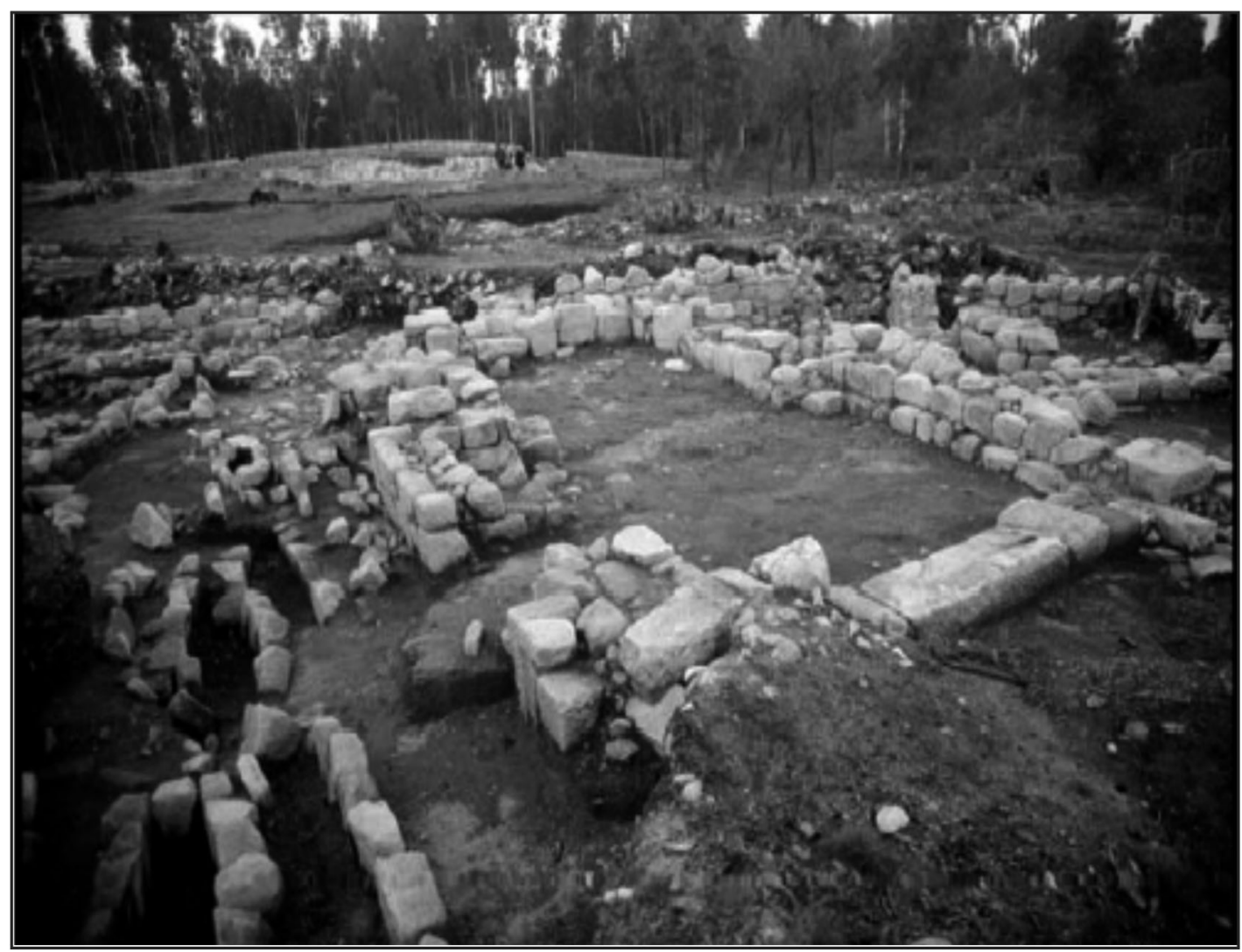

Fig. 3. Vicus de Alvarelhos (Trofa).

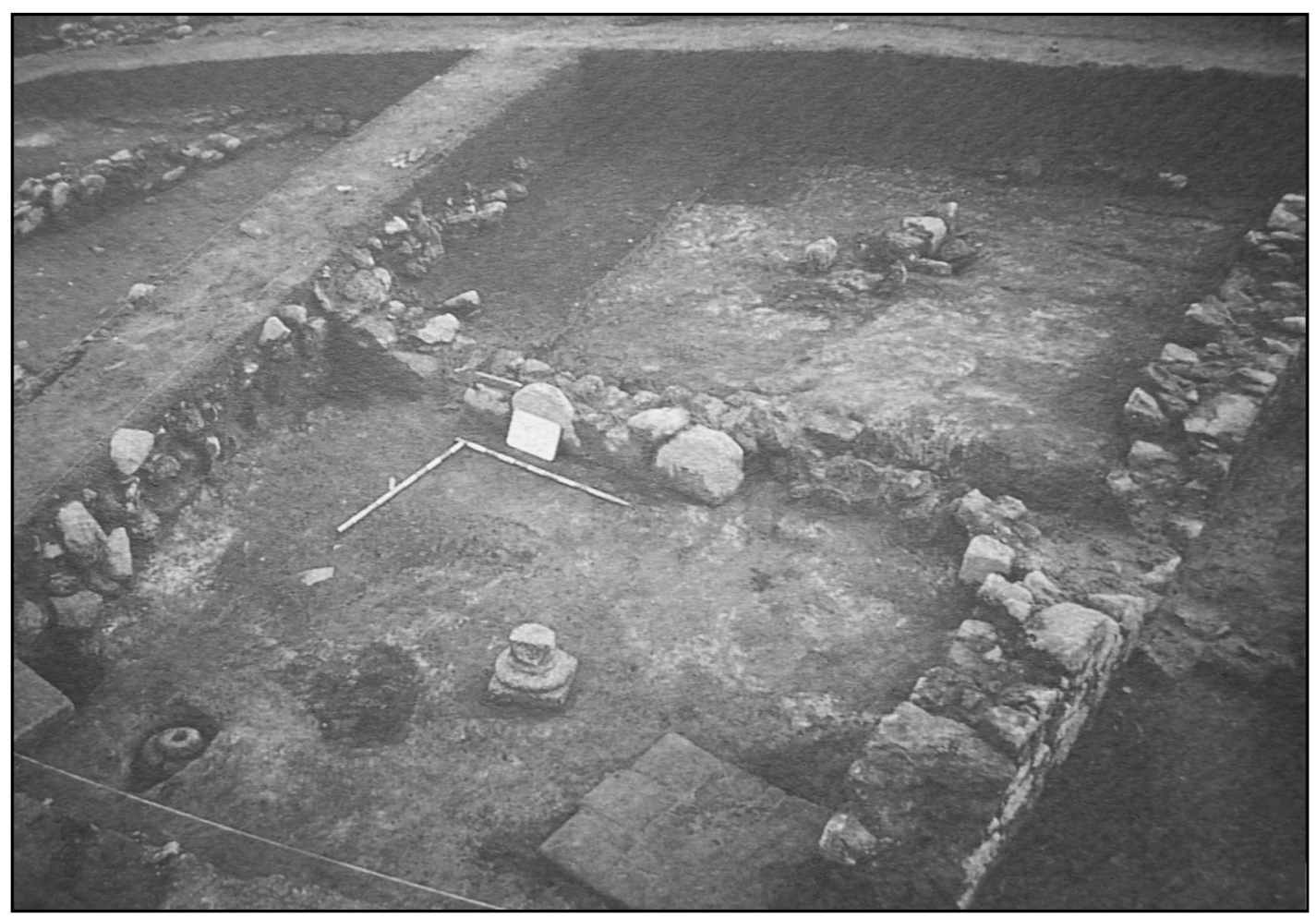

Fig. 4. Vicus de Baños de Bande (Ourense) (RODRÍGUEZ COLMENERO-HERVES RAIGOSO, 1995) 


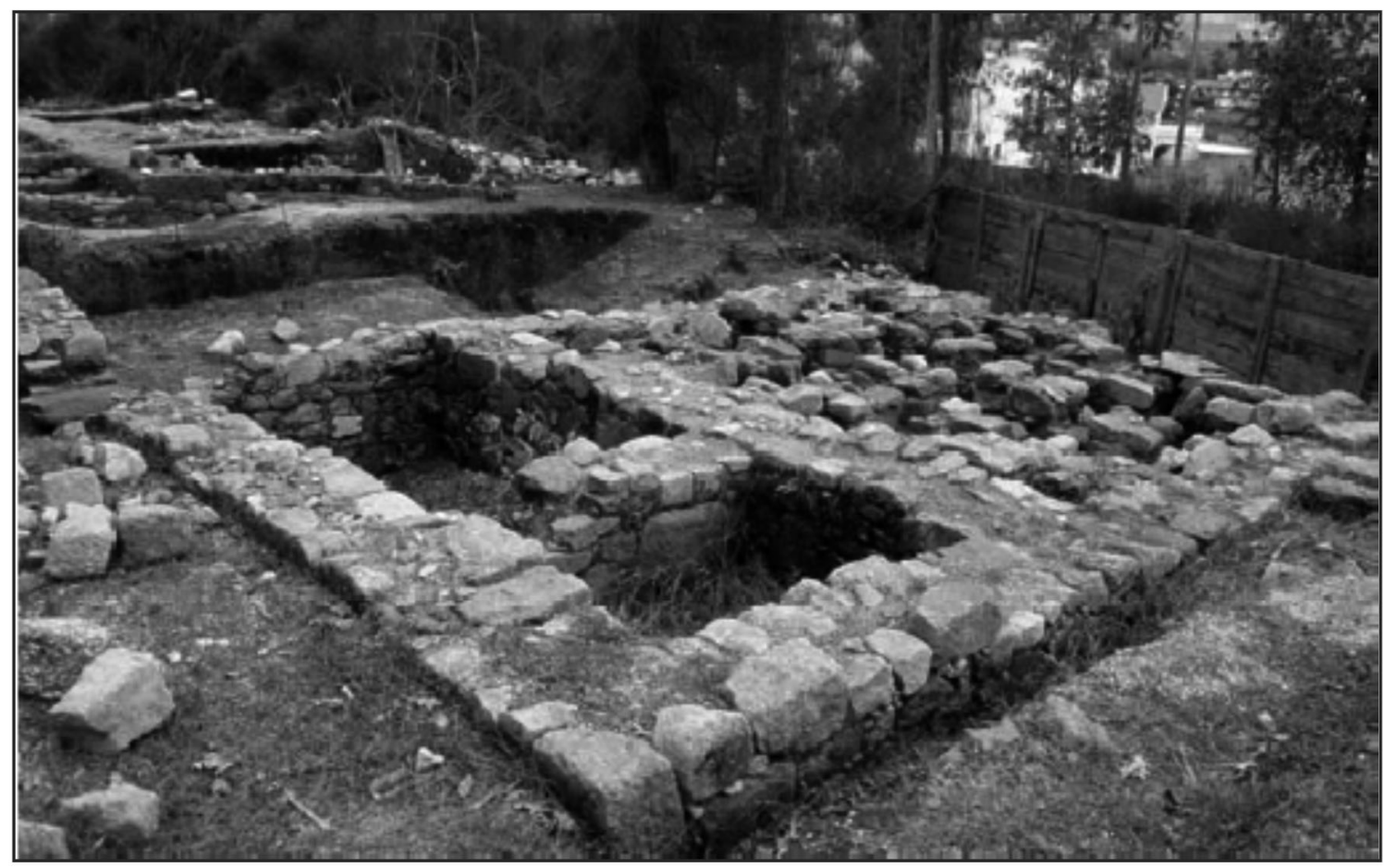

Fig. 5. Asentamiento rural de época romana de Perrelos (Vila Nova de Famalicâo).

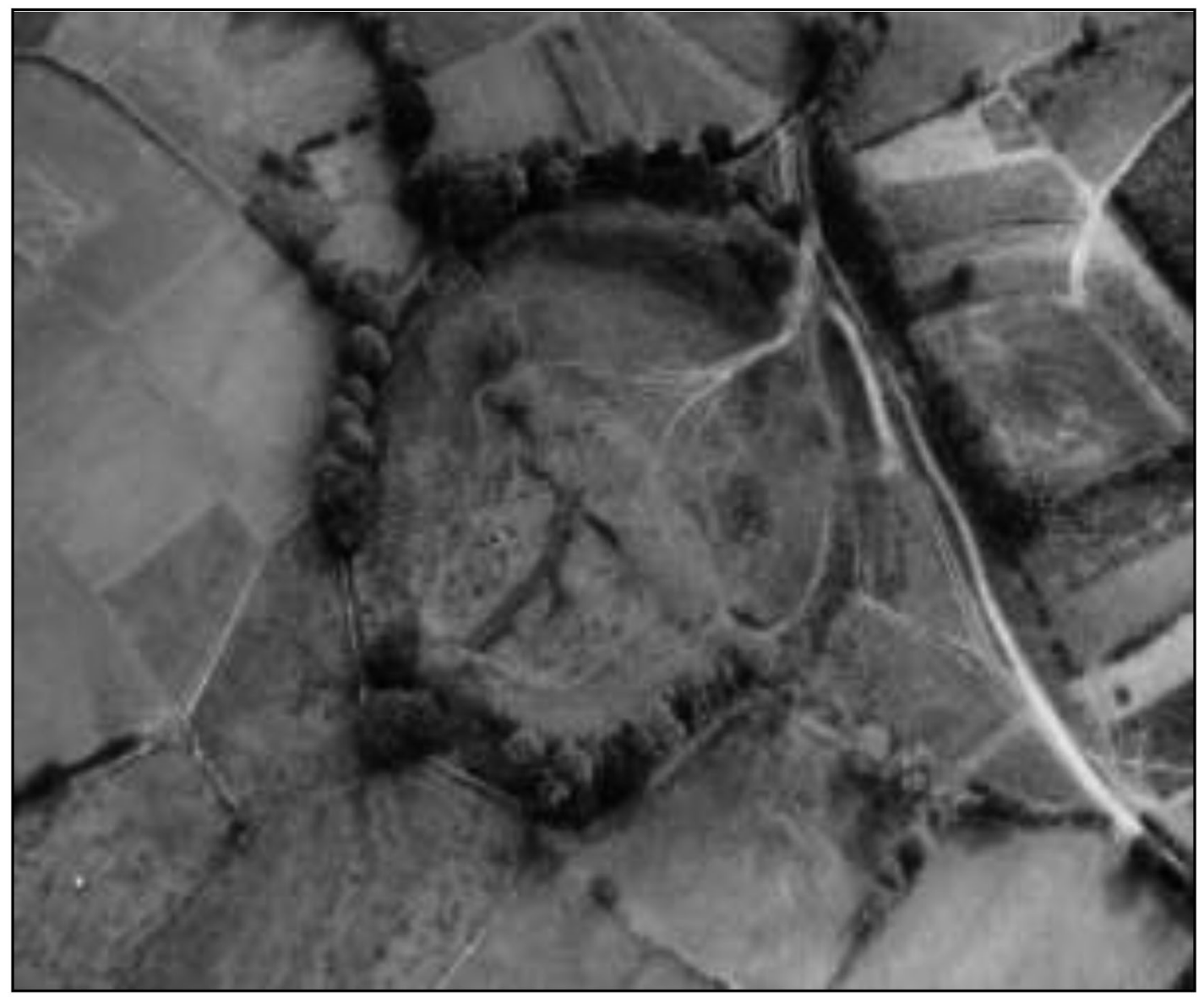

Fig. 6. Castro de Morgade 


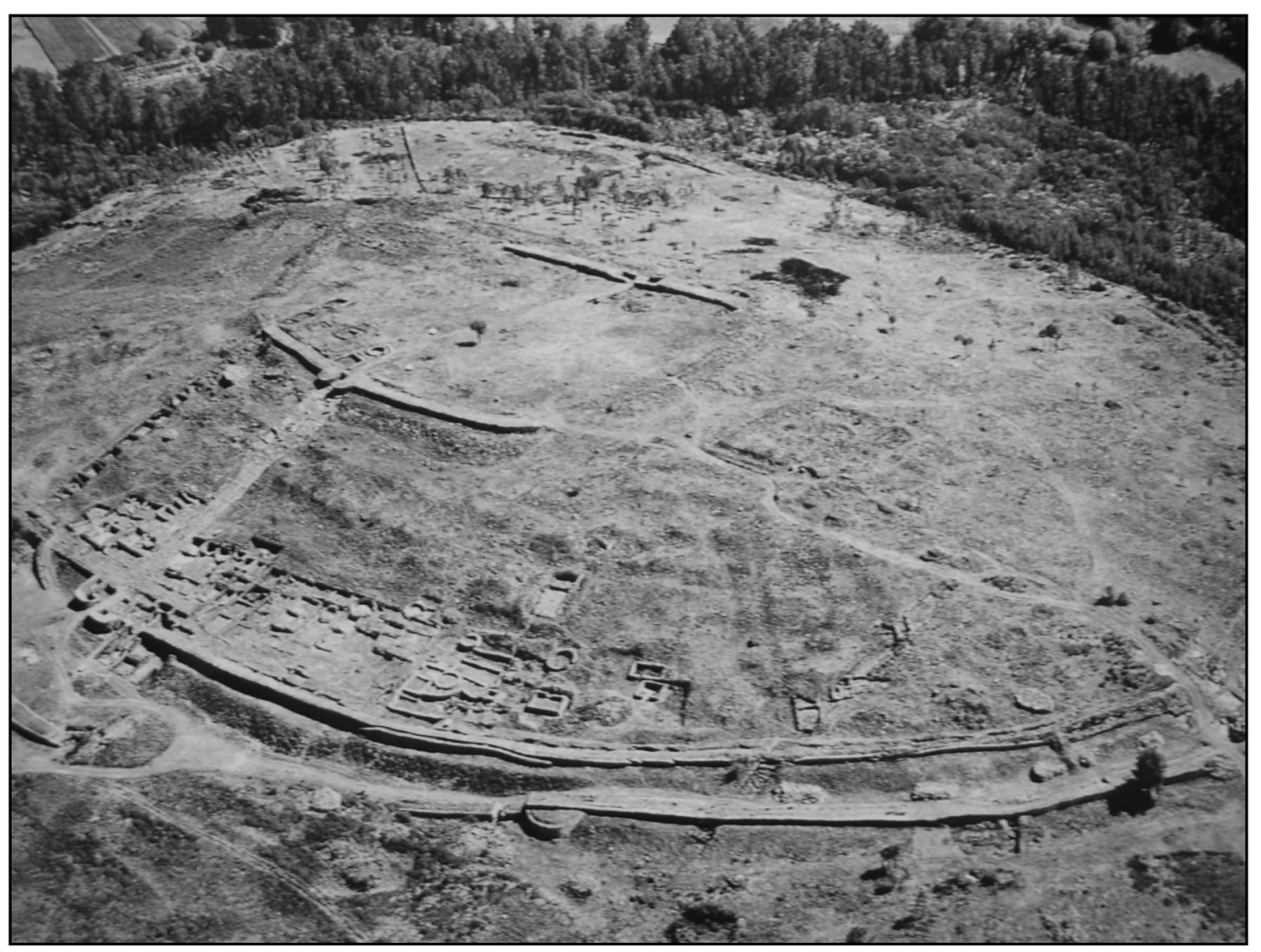

Fig. 7. Castro de San Cibrán de Las (Ourense).

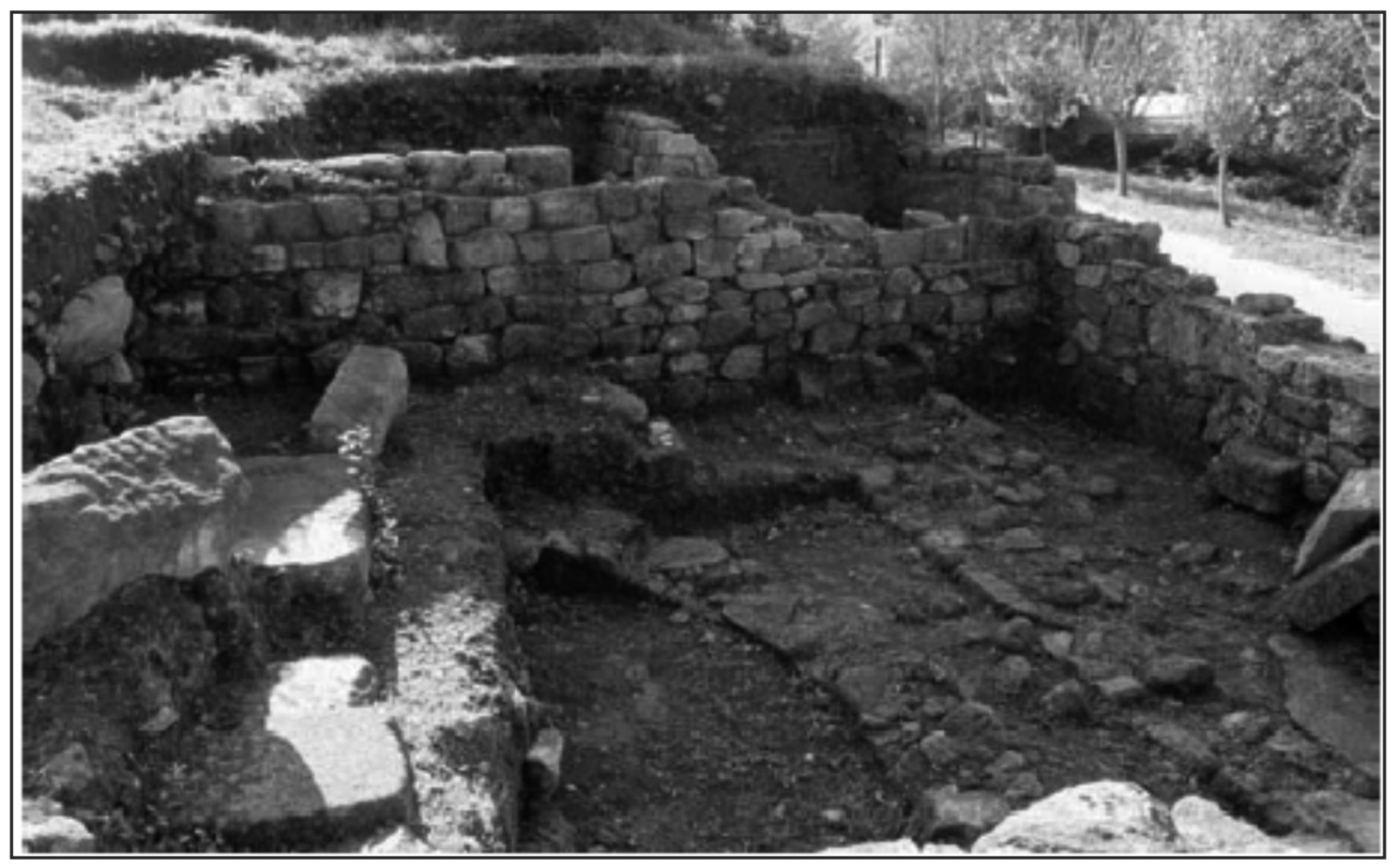

Fig. 8. Asentamiento rural de época romana de Lovelhe (Vila Nova de Cerveira). 


\section{LÁMINA XXII}

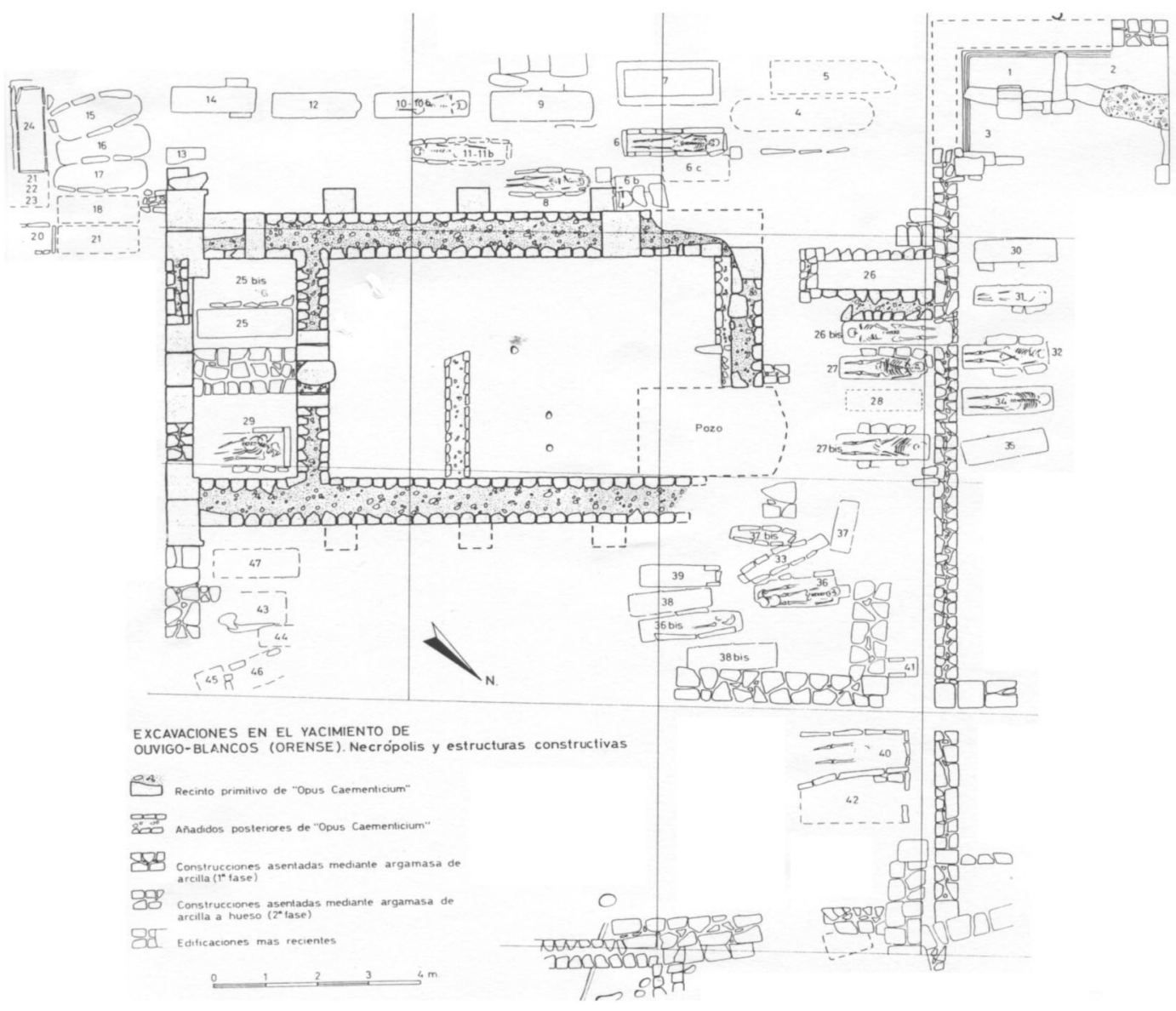

Fig. 1: Ouvigo, Blancos (Ouvigo). Necrópolis y estructuras constructivas (RODRÍGUEZ COLMENERO, 1985)

Fig. 9. San Verísimio de Ouvigo (Blancos, Ourense) (RODRÍGUEZ COLMENERO, 1985) 


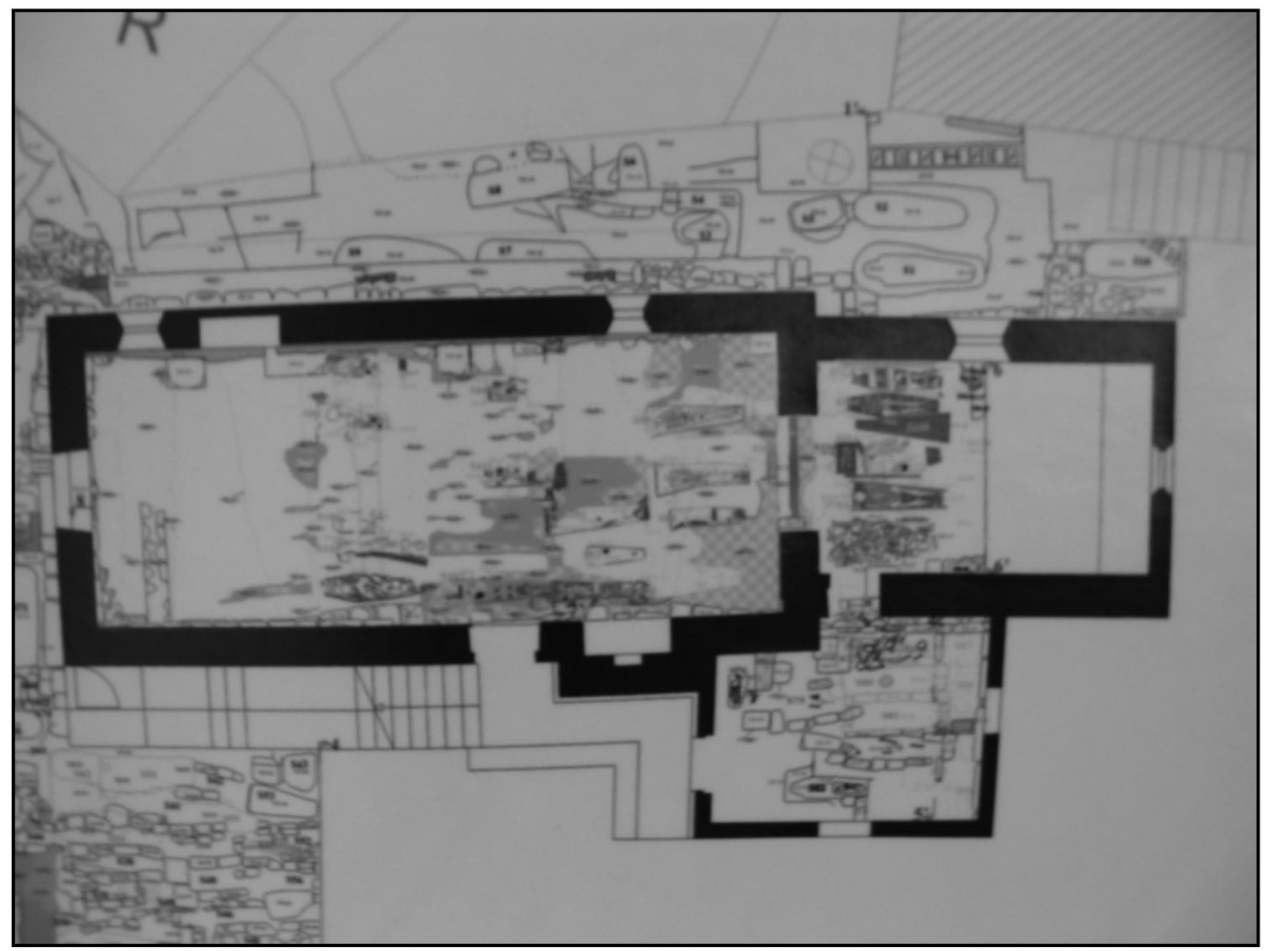

Fig. 10. Iglesia tardo-antigua de Tongobriga (siglo VI) en Freixo (Marco de Canaveses) (Fotografía del autor).

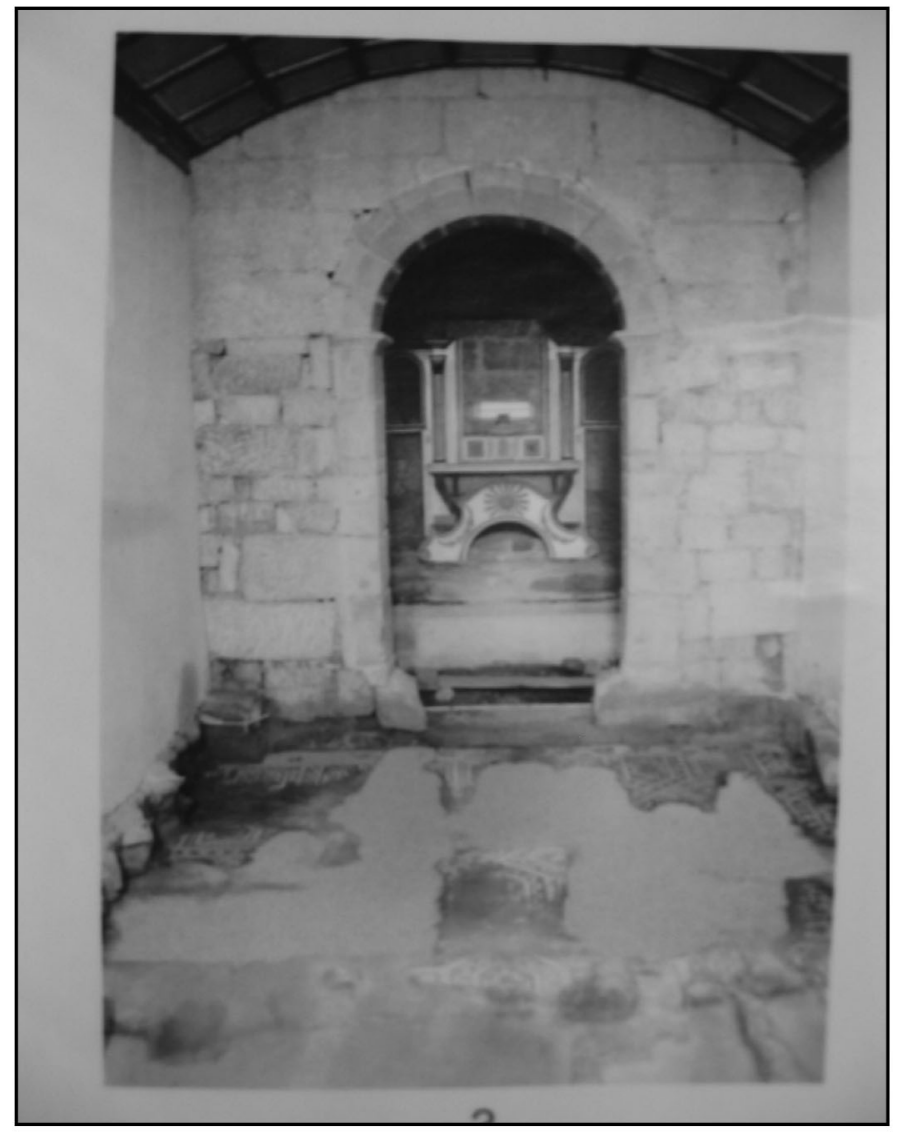

Fig. 11. Iglesia tardo-antigua de Tongobriga (siglo VI) en Freixo (Marco de Canaveses) (Fotografía del autor). 


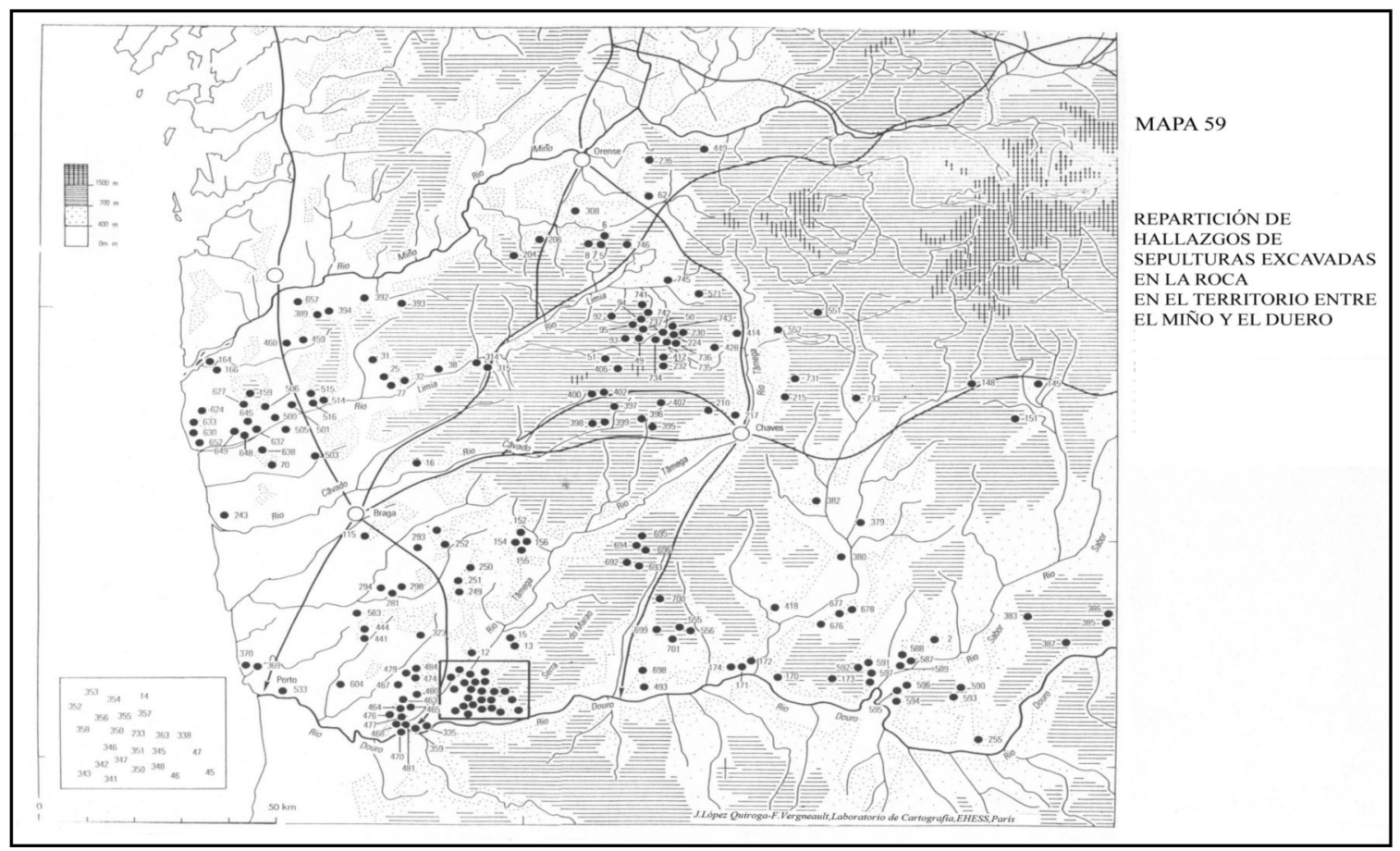

Fig. 12. Tumbas excavadas en la roca entre el Miño y el Duero (LÓPEZ QUIROGA, 2004)

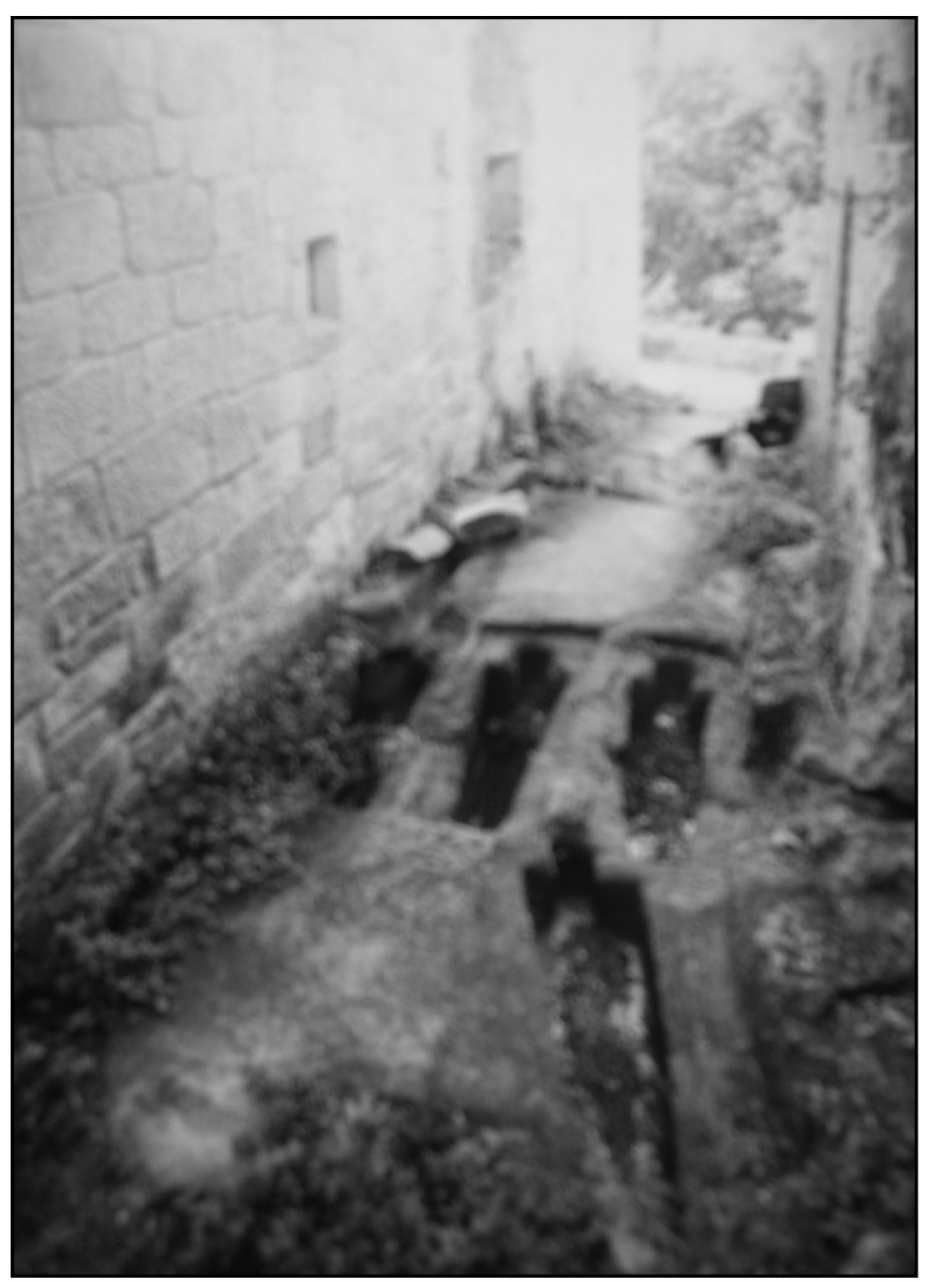

Fig.13. Sepulturas excavadas en la roca (San Pedro de Rocas, Esgos, Ourense) (Foto del autor) 


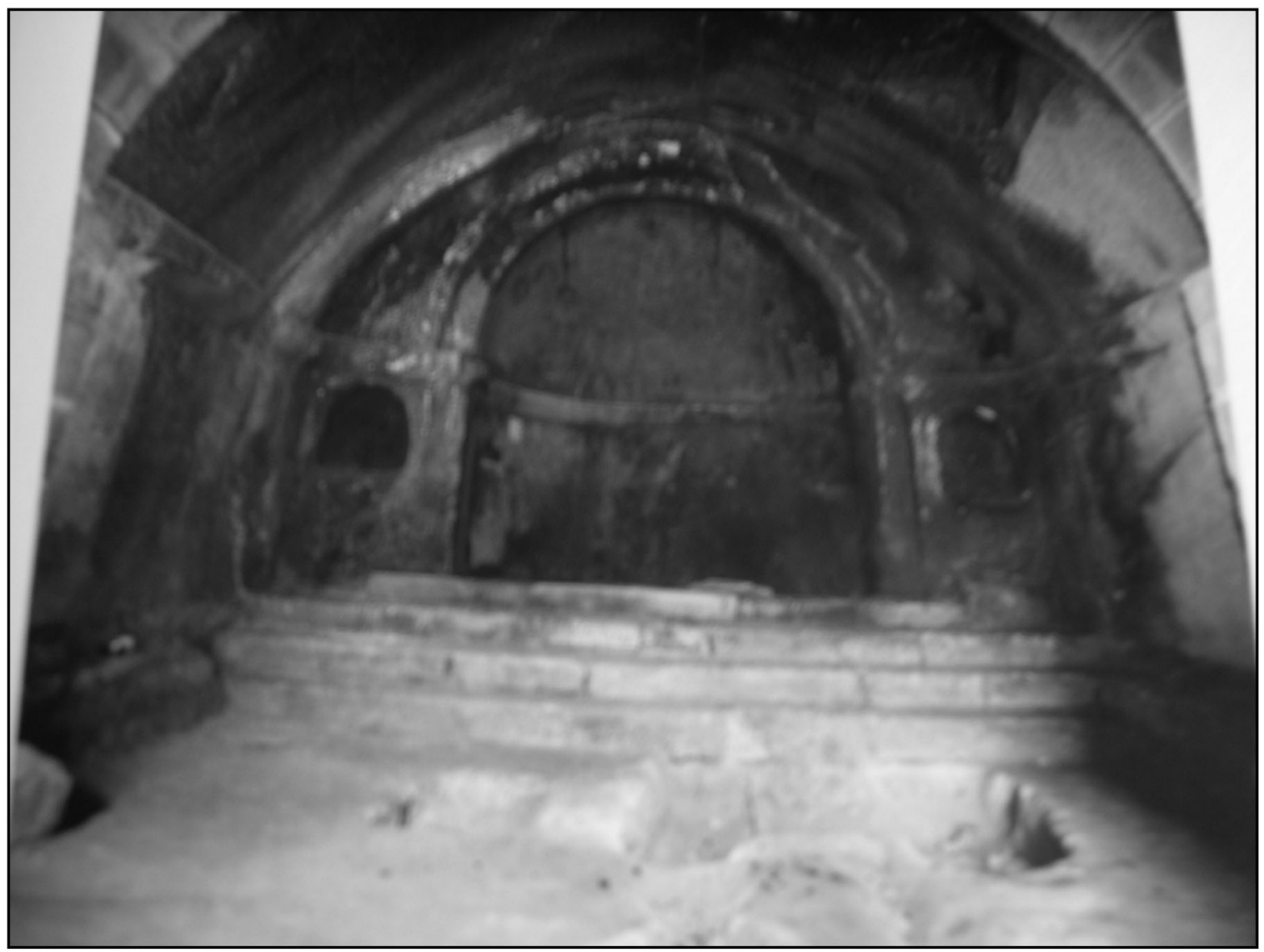

Fig. 14. Capilla central excavada en la roca en San Pedro de Rocas (Esgos, Ourense). Se aprecian en primer plano las inhumaciones infantiles ubicadas en lugar privilegiado respecto al conjunto del cementerio y respecto a los ámbitos espaciales de tipo cultual (Fotografía del autor).

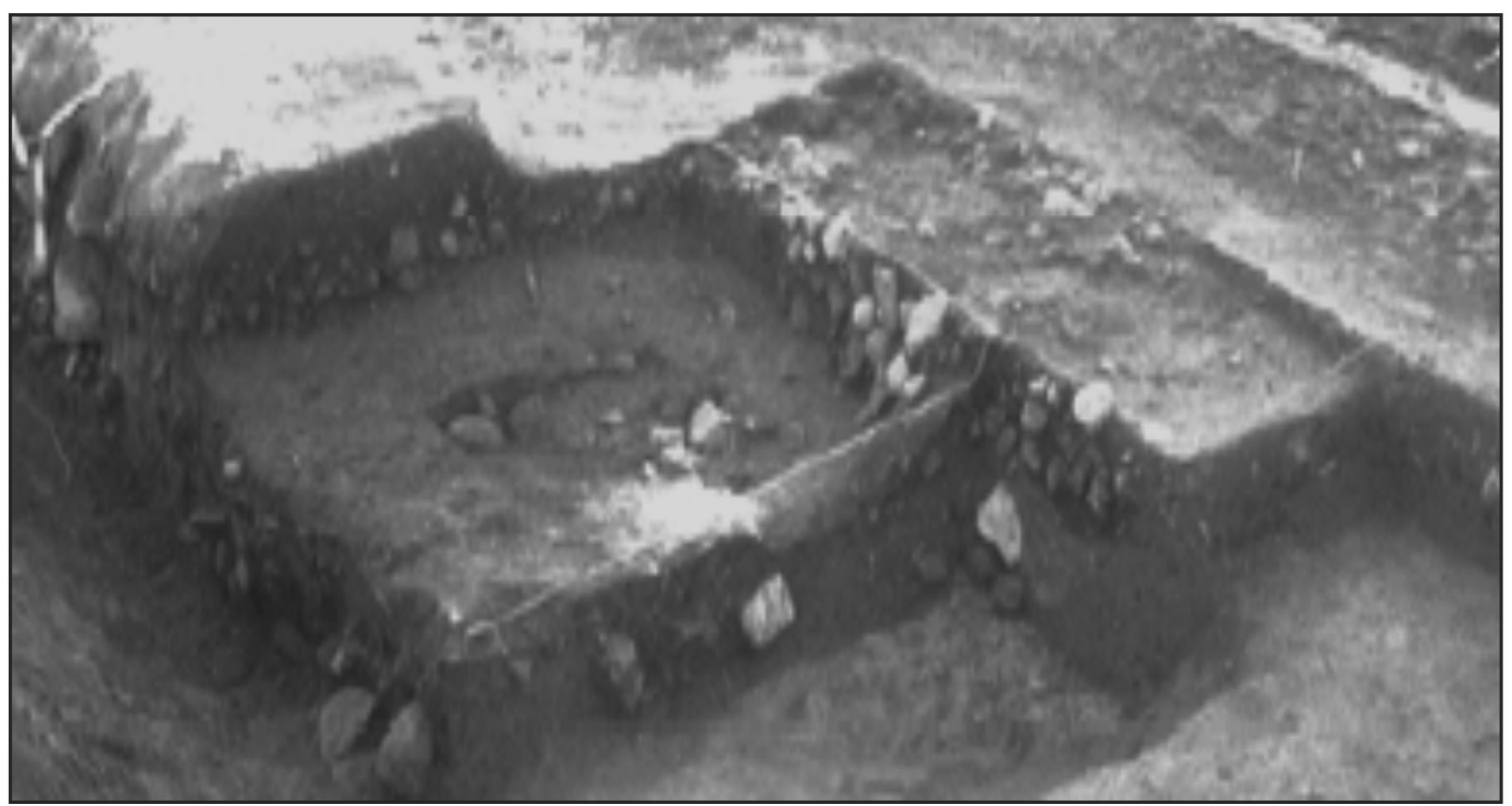

Fig. 15. Yacimiento de "As Pereas" (San Pedro de Trasalba, Amoeiro). 